\title{
Researchers from Academia, Government, and Industry Come Together at the 2006 MRS Spring Meeting
}

\author{
www.mrs.org/spring2006
}

From microelectronics device processing and fabrication, to complex and biological nanoscale materials and systems, to energy and the environment, the 2006 Materials Research Society Spring Meeting, held April 17-21 in San Francisco, brought together over 3,500 attendees from all sectors of the global materials science and engineering communities. Nearly 3,000 oral and poster presentations were featured (from 37 technical symposia) in a program put together by Meeting Chairs J. Charles Barbour (Sandia National Laboratories), Paul S. Drzaic (Alien Technology Corporation), Gregg S. Higashi (Intel Corporation), and Viola Vogel (Swiss Federal Institute of Technology).

The symposia were organized within six clusters: energy, bio-organic/inorganic composites, nano-/microstructures, smart materials, mechanical behavior, and electronics/photonics. In addition, the meeting offered tutorials, an equipment exhibit, and various special events and activities.

Craig Barrett, chair of the board for Intel Corporation, who gave the plenary address 13 years ago, returned as the plenary speaker to discuss the digital revolution and how both competition and opportunities will grow as more and more people engage in a digital economy. A lot has changed since he last spoke to this audience. Barrett said that the digital revolution has become an engine of change from a global perspective, and over the past 10 years has brought three billion people from emerging economies of the world into its fold. He demonstrated how Moore's law regarding the doubling of the number of transistors on a microprocessor approximately every 18 months continues to hold true after 40 years and will likely do so over the next 15 years at least. However, newer technologies and paradigms are emerging, such as nanotechnology and molecular electronics, which will lead away from the traditional CMOS technologies used in silicon microelectronics. Industries that resist change will be in trouble, he said. Nothing is better than investing in good people and ideas to create successful organizations, he said. Barrett expressed how this formula has worked successfully for Intel.

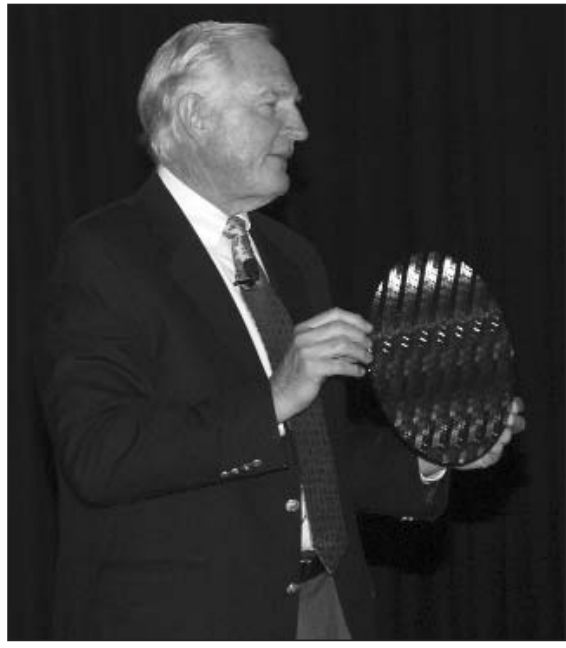

Craig Barrett, chair of the board for Intel Corporation, holds up a silicon wafer during his plenary address on April 19 at the 2006 Materials Research Society Spring Meeting in San Francisco.

\section{Microelectronics Device Processing and Fabrication}

The symposia addressing microelectronics devices offered talks ranging from amorphous and polycrystalline silicon thin films to chalcogenide phase-change materials. Cree Inc. has come a long way in the development of silicon carbide single crystals. D. Malta from Cree described, in Symposium B, experiments to increase the lifetime of minority carriers (holes) in the bulk material for the fabrication of $p-i-n$ diodes with high breakdown voltages. While he was careful not to give away too much information due to intellectual property considerations, he was able to showusing several measurement techniquesthat an anneal at $2600^{\circ} \mathrm{C}$ with a slow cooldown over $12 \mathrm{~h}$ increased the lifetime from less than $10 \mathrm{~ns}$ to $30 \mu \mathrm{s}$. Researchers from Cree were also able to show that the effects were not due to trapping.

In another presentation in Symposium B, M. Fanton (PSU) and colleagues from CMU and NRL discussed their research on growing $\mathrm{SiC}$ by CVD. They were able to control the carbon-to-silicon ratio and tested the resulting materials for low boron concentrations and nitrogen concentrations that could be varied over a wide range (from $1 \times 10^{16}$ to $1 \times 10^{19}$ atoms / $\mathrm{cm}^{3}$ ). They provided a clean solution to non-uniform growth by the extraction of exhaust gases from the top of the reactor rather than the bottom.

In Symposium H, research on the structure of the amorphous state of $\mathrm{Ge}_{2} \mathrm{Sb}_{2} \mathrm{Te}_{5}$ brought significant debate. A. Kolobov (AIST; CNRS) and co-workers have published a model that features tetrahedrally coordinated germanium in a perturbed, crystalline environment. This was deduced from XAFS data on material that was initially polycrystalline and then switched to the amorphous state under laser excitation in device structures. Several other presentations either reviewed or expanded on this model. Theoretical calculations were also presented that were consistent, in all or in part, with this structural model. In contrast, M. Paesler (NCSU) reported XAFS on as-deposited $\mathrm{Ge}_{2} \mathrm{Sb}_{2} \mathrm{Te}_{5}$. This material was highly disordered, showing no evidence for intermediate or long-range order by fluctuation electron microscopy. In contrast, nucleation studies suggested that the laser-reamorphized phase representing the principal commercial application of $\mathrm{Ge}_{2} \mathrm{Sb}_{2} \mathrm{Te}_{5}$ may contain a significant density of nucleation centers, implying that the laser-reamorphized material may be structurally different than those reported by the Paesler group (including researchers from the University of Utah and IIT, Kanpur). The Paesler group deduced that its material had essentially fourfold Ge, twofold Te, and threefold Sb, with some homopolar Ge-Ge bonds, and roughly $17 \%$ threefold coordination on the Te atoms. The Paesler group also reported a small component of anomalously short $\mathrm{Sb}-\mathrm{Te}$ bonds. This is to be contrasted with the laser-amorphized material for which neither the short $\mathrm{Sb}-\mathrm{Te}$ nor $\mathrm{Ge}-\mathrm{Ge}$ were found. The two competing pictures require resolution.

\section{Photonics, Electronics, Magnetics, and Sensors}

The cluster of symposia on photonics, electronics, magnetics, and sensors announced advances made in organic, inorganic, and hybrid materials systems, as well as the latest breakthroughs in nanowires and nanostructured materials systems. Nanobelts, nanosprings, nanorings, nanobows, nanohelices, and nano- 
spirals can all be grown in a catalyst-free, single-step thermal evaporation process from $\mathrm{ZnO}$, as reported by Z.L. Wang (Georgia Tech.) in Symposium R. The driving force behind the formation of these shapes is the polar surface of $\mathrm{ZnO}$; curling into circular or helical structures reduces the dipole moment of the structure. Simultaneously, the elastic energy of the system competes with the dipolar energy to determine the equilibrium structure. These shapes are grown in a freestyle mode, with no catalyst present; a gold catalyst would selectively nucleate nanorods or nanowires. By controlling the pressure of the system during crystal growth, Wang and colleagues can substantially control the yield of a desired morphology. Such control could prove to be significant in future applications of these $\mathrm{ZnO}$ nanostructures, which are optically transparent, piezoelectric, pyroelectric, and biocompatible. Nanohelices can adopt left- or right-handed conformations. Wang reported that these helices contain superlattices consisting of two stripes of the same material with different ordering parameters. One stripe has a polar surface and the other a nonpolar one. This superlattice forms spontaneously when mismatch dislocations appear in the crystal.

By introducing carbon nanotubes into polyaniline organic fibers, G. Wallace and colleagues at the University of Wollongong, Australia, plan to strengthen the conductive polymer to create wearable artificial muscles, such as a glove for restoring use to an injured hand. In his presentation in Symposium S, Wallace said that conductive polymers like polyaniline expand and contract during the oxidation/reduction cycle, providing a potential mechanism for artificial muscle development. However, the low strength of the polymer precludes its use in this application. Adding MWCNTs to the polyaniline in a solvent that stabilized the MWCNTs increased the tensile strength up to 250 $\mathrm{MPa}$ and boosted the electrical conductivity of polyaniline fibers. The resulting fibers showed much improved expansion and contraction properties under load, making them possible candidates for artificial muscle materials.

In another area of study, the desire to place large telescope mirrors in space to probe the darker recesses of the universe is running into practical materials prob- lems: as standard mirrors get large, they suffer from structural instabilities and require sophisticated support structures to maintain their precise focusing abilities. In a presentation in Symposium O, M. Ermold (Drexel) proposed the use of holographic optical elements as a potential solution. Lightweight, holographic, polymer dispersed liquid-crystal gratings made from nematic liquid crystals, multifunctional polymers, and photoinitiators can be used as electrically controlled beam steering and focusing optics. Ermold presented models of the optical properties of the films, including estimates of the amount of phase-separated liquid crystal in these thin films. Development of these holographic devices may produce lightweight, stable optics for space-based telescopes in the future.

\section{Complex and Biological Nanoscale Materials and Systems}

Complex materials behavior and biological nanoscale systems were explored in symposia with topics ranging from nanomanufacturing to the mechanics of nanoscale systems to biological machines and nanoscale probes for molecular bio-

\section{ACRONYM KEY}

1D: one-dimensional

2D: two-dimensional

3D: three-dimensional

ADP: adenosine diphosphate

AFOSR: Air Force Office of Scientific Research

AFRL: Air Force Research Laboratory

AIST: Agency of Industrial Science and

Technology

AMOLED: active-matrix OLED

ANL: Argonne National Laboratory

ARL: Army Research Laboratory

ATP: adenosine triphosphate

BJT: bipolar junction transistor

BNL: Brookhaven National Laboratory

CMOS: complementary metal oxide semiconductor

CMU: Carnegie Mellon University

CNR-IMM: Consiglio-Nazionale delle

Ricerche-Istituto per la Microelettronica e Microsistemi

CNRS: Centre National de la Recherche Scientifique

CNT: carbon nanotube

CVD: chemical vapor deposition

DOE: Department of Energy

EL: electroluminescence

EOT: equivalent oxide thickness

ETH: Swiss Federal Institute of Technology in Zurich

FeRAM: ferroelectric random-access memory

FET: field-effect transistor
GE: General Electric

Georgia Tech: Georgia Institute of Technology

HP: Hewlett-Packard

IBMT: Institut Biomedizinische Technik

IC: integrated circuit

IIT: Indian Institute of Technology

ISTEC: International Superconductivity

Technology Center

ITO: indium tin oxide

IZO: indium zinc oxide

JHU: Johns Hopkins University

KAIST: Korea Advanced Institute of Science and Technology

LANL: Los Alamos National Laboratory

LBNL: Lawrence Berkeley National Laboratory

LC: liquid crystal

LED: light-emitting diode

LLNL: Lawrence Livermore National Laboratory

MEMS: microelectromechanical systems

MIT: Massachusetts Institute of Technology

MOSFET: metal oxide semiconductor

field-effect transistor

MPI: Max Planck Institute

MRSEC: Materials Research Science and

Engineering Center

MWCNT: multiwalled carbon nanotube

NASA: National Aeronautics and Space

Administration

NCSU: North Carolina State University

NIMS: National Institute for Materials Science

NIST: National Institute of Standards and

Technology
NREL: National Renewable Energy

Laboratory

NRL: Naval Research Laboratory

NSF: National Science Foundation

OLED: organic light-emitting diode

ONR: Office of Naval Research

ORNL: Oak Ridge National Laboratory

PARC: Palo Alto Research Center

PEDOT: poly(3,4-ethylenedioxythiophene)

PEEM: photoemission electron microscopy

PNNL: Pacific Northwest National Laboratory

PSU: Pennsylvania State University

PV: photovoltaic

RAM: random-access memory

RFID: radio-frequency identification

SIUC: Southern Illinois University at

Carbondale

SNL: Sandia National Laboratories

SOI: silicon-on-insulator

STEM: scanning transmission electron

microscopy

STM: scanning tunneling microscopy

SWNT: single-walled carbon nanotube

TEM: transmission electron microscopy

TFT: thin-film transistor

UCLA: University of California, Los Angeles

UCSC: University of California, Santa Cruz

UIUC: University of Illinois at

Urbana-Champaign

XAFS: $x$-ray absorption fine structure

XPS: $x$-ray photoemission spectroscopy 
imaging. In his Symposium AA talk, "Breaking the Nanometer Barrier in Single Molecule Studies-or-How a Biophysicist Watches DNA Transcription," S.M. Block (Stanford) detailed his group's work in understanding the operation of the RNA polymerase enzyme in reading and transcribing DNA. The work has been so successful that the researchers can read the DNA sequence as fast as transcription takes place. Block and his colleagues designed an ultralownoise optical trap for the work. This involved replacing the air in the system with helium to reduce laser distortion due to refraction, and designing a novel force clamp that permits angstrom-level measurements to be made with confidence. Using their optical trap, the researchers watched RNA polymerase "walk" along a DNA molecule at $1 \AA$ /s in real time in an aqueous solution at room temperature. They could see-in previously impossible-to-see detail-each base-pair step the RNA polymerase made along the DNA molecule, including the pauses and the backtracking that occur periodically when the RNA polymerase makes a mistake in transcription and goes back to fix it. The accuracy of the real-time sequencing of DNA was confirmed by an experiment in which 29 of 30 DNA bases were correctly identified in about a minute of data collection time.

Biomolecular motors, such as the motor protein kinesin, can act as independent agents in a liquid environment, capable of driving directed transport or active self-assembly processes. Kinesin consumes ATP as it walks along the microtubules in 8-nm steps, converting the stored chemical energy in ATP into mechanical work. H. Hess (Univ. of Florida, Gainesville) and his colleagues are attempting to use these properties to detect and round up antigens in the body, measure their concentration, and transport them to a desired site. In his presentation in Symposium AA, Hess described the process of making a biosensor based on molecular shuttles through sequential assembly of a double-antibody sandwich on a biotinylated microtubule. Starting with a kinesin-coated substrate, a microtubule is laid down and coated with streptavidin, followed by a biotinylated antibody layer. This antibody layer can capture an antigen, which is detected by binding a fluorescently labeled second antibody. Microtubules carrying such a double antibody sandwich can be transported by kinesin motors for further aggregation of collected antigens. In a similar setup, functionalized microtubules can be assembled into wires and

\section{Special Symposium Honors the Contributions of John M. Poate}

Symposium LL, a special forum held in recognition of the contributions of John M. Poate, focused on ion beams, defects, laser annealing, and thin-film work done primarily during Poate's tenure at Bell Labs. Rather than a mere retrospective, the symposium focused on fields stimulated by Poate, leading toward cutting-edge applications of the processes and underlying science spurred by those earlier times. As depicted by those who worked with Poate-colleagues who then moved research forward as they funneled in or fanned out across the globe-the cascading effects of Poate-colleague interactions paralleled the cascading effects of ion beams themselves. Walter Brown, who originally recruited Poate to Bell Labs in 1971, opened the session with a brief history of Poate's move into ion implantation and ion-beam channeling and then his journey through gettering, laser annealing, interfaces, amorphous silicon, GaAs, buried oxides, Er in silicon, luminescence, and other areas. Poate was a leader rather than a follower. His pioneering approach was perhaps best summed up by symposium organizer Jim Williams, who quoted Poate as saying, "We write the literature. We don't read the literature."

Poate's long-time colleague and associate at Bell Labs, Dale Jacobson (SemEquip Inc.), gave the first of the technical talks, describing molecular ion implantation, a technique that addresses the growing demand for lower-energy, high-dose implants by accelerating clusters of atoms that split apart when bombarding a surface. The lower energy, shallower implants, and high doses satisfy needs for shrinking electronic device sizes and high throughput. In a shorter encounter, still resulting in important effects, Sjoerd Roorda (now at the University of Montreal) collaborated with Poate for only a few months at Bell Labs, but represented the start of a stream of Dutch graduate students who flowed into Bell Labs over the years. He recalled writing the operating manual with Jacobson for a new 1.7-MV accelerator, with the last of a set of simple instructions being simply to "optimize all parameters." Roorda talked about using ion beams of $\mathrm{kV}$ and MV energies to make, modify, and study materials on a nanometer length scale. Poate's many interactions, particularly across international and interdisciplinary lines, speak to the depth and breadth of his talents, which have led to continuing camaraderie, frank discussions, and critical research accomplishments.

This symposium was sponsored by Applied Materials Inc. and Axcelis Technologies Inc.

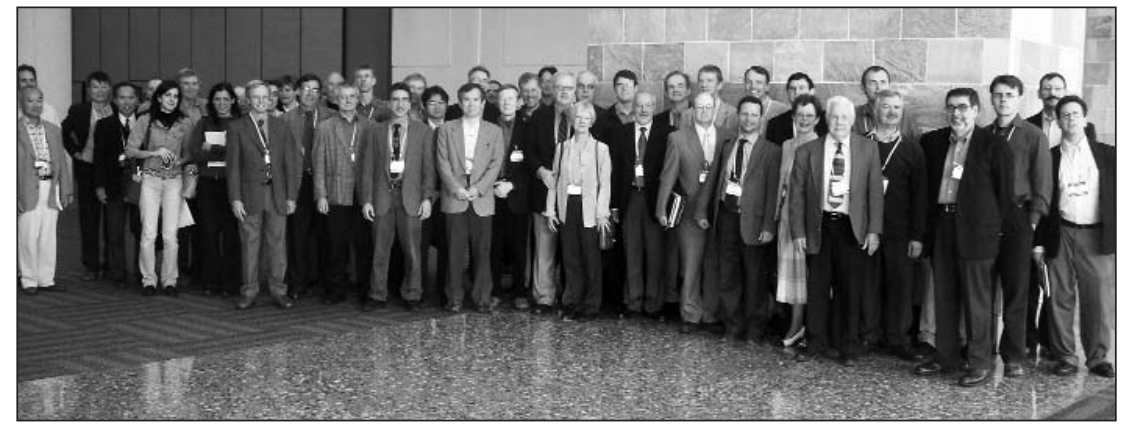

Participants in a special symposium held in honor of the contributions of John M. Poate, formerly of Bell Labs.

spools by kinesin motors, thus creating order at the expense of ATP fuel.

In Symposium CC, D.R. Kipke (Univ. of Michigan) described implantable microscale neural interface devices-probes that interface with the brain. His group is developing neural probe platform technologies to provide combined electrical and chemical interfaces at the cellular level to selective areas of the brain. The goal is for long-term recording, sensing, and drug delivery, integrating both electrical and chemical domains. First-generation probes relied on electrode arrays of microwires. Second-generation devices progressed to silicon MEMS. Third-generation devices move into the realm of flexible integrated electronics, including integration of drug delivery. Kipke's group has developed parylene-based microfabricated multichannel implantable devices to stimulate and/or record from populations of neu- 
rons for long periods of time. However, Kipke said, successful recording of chronic neural activity is greatly affected by the tissue response to the penetrating neural probes, and currently, the responses are unpredictable. To better understand the tissue damage from the electrode insertion, the researchers examined local changes such as in the $\mathrm{pH}$ level, finding that faster insertion of the probe led to smaller $\mathrm{pH}$ fluctuations, and presumably less tissue damage.

\section{Energy and Environment}

Popular at the 2005 MRS Fall Meeting, a cluster of symposia on energy and environment was carried over into the Spring Meeting with the added focus on materials research in hydrogen storage and water purification and their effects on applications. Efforts to store hydrogen at room temperature in structures made from unmodified CNTs are not promising, according to J.K. Kang (KAIST). Instead, in his Symposium EE presentation, Kang proposed a Ni/CNT hybrid structure that he said is effective for practical hydrogen storage. By creating 0.6-nm pores on the stems of SWNTs and dispersing $\mathrm{Ni}$ nanoparticles into these pores, with each $\mathrm{Ni}$ atom capable of bonding reversibly to six $\mathrm{H}_{2}$ molecules, Kang said 4.5 wt. $\% \mathrm{H}_{2}$ can be stored and delivered at room temperature. Although this still falls short of the $6.5 \mathrm{wt} . \% \mathrm{H}_{2}$ targeted by the U.S. Department of Energy for effective use of hydrogen in automobiles, it is an improvement over unmodified CNT storage devices.

Every year, two million people die from diseases contracted from unhealthy drinking water, C.J. Curtis (NREL) said in his Symposium JJ presentation on new materials for water purification. In the quest for inexpensive and simple solutions to water purification, he reported on an approach that relies on high-surface-area nanomaterials that actively absorb contaminants but do not restrict flow like membranes do. Curtis's group constructed composites from boehmite $\left([\mathrm{AlO}(\mathrm{OH})]_{n}\right)$ nanofibers synthesized by a hydrothermal process from $\mathrm{Al}(\mathrm{OH})_{3}$. These fibers are $2 \mathrm{~nm}$ wide and hundreds of nanometers in length, with large surface areas. The key to their success, Curtis said, was to use hydrothermal synthesis to integrate the boehmite with support media such as cellulose or glass fibers. The hydroxyl groups and small size make these materials very active filter elements. Filters fabricated from these fibers removed bacteria and viruses from water very efficiently (>99.9999\% removed) by irreversibly binding the pathogens. These filters were also used to remove a variety of metal ions and ion mixtures from water.

Another major concern in the purification of water is to remove contamination caused by particulates and heavy metals. In Mexico, it has long been known that an extract from Opuntia ficus-indica, or the prickly pear cactus, which grows in abundance in various regions of Mexico, can remove turbidity in water. In his presentation in Symposium JJ, K. Young (Univ. of South Florida) described the use of mucilage, an extract from this cactus, to remove turbidity as well as arsenic from drinking water. Young found that both a gelling extract as well as a non-gelling extract from the cactus was a better flocculating agent than $\mathrm{Al}_{2}\left(\mathrm{SO}_{4}\right)_{3}$, which is commonly used now. In addition, the gelling extract was very effective in removing arsenic, depending on the concentration of arsenic present in the water.

For further details on the research results reported at the 2006 MRS Spring Meeting, see the symposium summaries that follow. Proceedings as well as additional meeting highlights are available online at www.mrs.org/spring2006.

\section{Thin-Film Si Electronics Feeds into Industry}

(See MRS Proceedings Volume 910)

Symposium A on Amorphous and Polycrystalline Thin-Film Silicon Science and Technology conveyed that thin-film silicon electronics is key to rapidly growing industries, that it keeps spinning off new applications, and that the tools for silicon film growth, modification, analysis, and modeling are becoming very sophisticated. F. Finger (FZ-Juelich, Germany) and M. Kondo (AIST, Japan) kicked off the Symposium with a full-day tutorial on "Thin Film Silicon Materials and Devices for Large-Area and Flexible Electronics." In a joint session with Symposium L, A. Nathan (Univ. of Waterloo) discussed the transistor and circuit requirements for AMOLED display backplanes, and T. Jackson (PSU) presented a flexible allorganic display. Presentations in the sessions focusing on solar cells included flexible solar module technology by A. Takano (Fuji, Japan), light management by J. Krc (Univ. of Ljubljana), and high efficiency cells by M. v.d. Donker (FZ-Juelich) and Q. Wang (NREL). T. Yoshinobu (Tohoku Univ.) led off a session on new applications of a-Si:H by presenting chemical imagers, and D. Hohlfeld (Univ. of Freiburg) described tunable optical resonators. A. Flewitt (Cambridge Univ.) exploited TFTs to understand defect kinetics, and I.P.M. Aarts (Eindhoven Univ.) applied cavity ring-down spectroscopy to study defects during growth. C.W. Teplin (NREL) examined the structural transition from low-temperature epitaxy of $\mathrm{Si}$ to amorphous growth. V. Dalal (Iowa State Univ.) placed the growth of microcrystalline silicon in perspective, S. Miyajima (Tokyo Inst. of Technology) deposited alloys of nanocrystalline silicon with carbon and germanium at very low temperature, S. Reynolds (FZ-Juelich) studied carrier transport mc-Si, and G. Yue (United Solar Ovonic Corp.) described the design of mc-Si solar cells for near-zero metastability. W. Yeh (Natl. Taiwan Univ.) illustrated the control of grain growth during laser crystallization of a-Si, a field covered by many other contributions.

Symposium Support: Corning Display Technologies; Fuji Electric Advanced Technology Co. Ltd.; Japan GoreTex Co. Ltd.; Kaneka Corp; MVSystems Inc.; NREL; ULVAC Inc.; and United Solar Ovonic Corp.

\section{SiC Developed for High-Power and High-Temperature Applications} (See MRS Proceedings Volume 911)

Silicon carbide $(\mathrm{SiC})$ is a very robust semiconductor material being actively developed for high-power and high-temperature applications, especially in the field of power electronics and sensors for harsh environments. Symposium B covered SiC growth, defects, and devices. Among the highlights from sessions devoted to bulk growth were the presentations by A. Souzis (II-VI Inc.) and D. Malta (Cree). M. Pons (LTPCN, INP, Grenoble) presented work on the modeling of $\mathrm{SiC}$ growth. Among the highlights of the sessions on epitaxial growth, F. La Via (CNR-IMM, Catania) and C. Thomas (Cornell) described $\mathrm{HCl}$-assisted $4 \mathrm{H}-\mathrm{SiC}$ epitaxial growth, while M. Loboda (Dow Corning Corp.) spoke of the advantages of CVD of $\mathrm{SiC}$ using chlorosilane gases. L. Rowland (GE Global Research) described epitaxy on different orientations, while B. Thomas (SiCED Electronics Development gmbH \& Co., Germany) and J. Zhang (SemiSouth) spoke of epitaxy for power devices. C. Hallin (INTRINSIC Semiconductor) reviewed the company's epitaxy research. In a session concerning dislocations in epitaxy, J. Sumakeris (Cree) spoke on the rationale for epitaxial growth on roughened surfaces, while K. Liu (NRL) described electron- and photoluminescence imaging of dislocations in $\mathrm{SiC}$. In a session devoted to semi-insulating $\mathrm{SiC}$, A. Cavallini (Univ. of Bologna, Italy) spoke on deep levels induced by neutron irradiation. Among the highlights of the sessions devoted to $\mathrm{SiC}$ materials issues, U. Starke (MPI, Stuttgart) spoke of the atomic structure of SiC surfaces, while R. Okojie 
(NASA Glenn Research Ctr.) spoke of process-induced deformations and stacking faults in $4 \mathrm{H}-\mathrm{SiC}$. In a session on epitaxy of 3C-SiC, P. Neudeck (NASA Glenn Research Ctr.) described recent advances in growth on step-free mesas, while S. Saddow (Univ. of South Florida) and M. Smith (Cambridge Univ., UK) spoke of 3C epitaxy on Si. In a session devoted to $\mathrm{SiC}$ contacts, A. Agarwal (Cree) spoke on $\mathrm{SiC}$ BJTs while S. Tsukimoto (Kyoto Univ.) spoke of the use of NiAl contacts. In a session on bipolar and other devices, $\mathrm{H}$. Chen (Stony Brook Univ.) described the influence of defects on Schottky device performance while T. Fawcett (Univ. of South Florida) discussed the thermal detection mechanism of $\mathrm{SiC}$ gas sensors. A. Schoner (Acreo $\mathrm{AB}$, Sweden) spoke of large-area vertical 3C-SiC MOSFETs. L. Feldman (Vanderbilt Univ.) gave a review on the $\mathrm{SiC}$ dielectric interface.

Symposium Support: Cree Inc.; Dow Corning Compound Semiconductor Solutions; INTRINSIC Semiconductor Corp.; SemiSouth Laboratories Inc.; and Sula Technologies.

\section{Progress Seen in Sub-Second Rapid Thermal Processing \\ (See MRS Proceedings Volume 912)}

In Symposium C on Sub-Second Rapid Thermal Processing for Device Fabrication, many presentations were given on the challenges faced with both flash and nonmelt laser annealing for annealing samples at temperatures of up to $1375^{\circ} \mathrm{C}$ for $\sim 1 \mathrm{~ms}$. Many talks were aimed at developing a better understanding of the point defect, diffusion, and activation kinetics that occur in this ultrashort time regime. In addition, N. Cagnet (STMicroelectronics, France) addressed the ability to control diffusion through the use of a variety of co-implant species including carbon, which is known to trap interstitials and is now being incorporated into manufacturing. K. Adachi (Toshiba Corp. Semiconductor Co., Japan) discussed the optimization of millisecond annealing with respect to both drain current and gate leakage, pointing out tradeoffs between improving the drain current for $p$-FETs but increasing the gate leakage for $n$-FETs. T. Yamamoto (Fujitsu Ltd., Japan) discussed developments in melt laser processes that suppress gate depletion, resulting in an increase of the ON current while suppressing the short-channel effect for sub-40-nm devices. V. Moroz (Synopsys Inc., Calif.) discussed recent advances in process simulation that account for defect evolution in both $\mathrm{Si}$ and SOI. Several talks addressed recent advances in metrology, including new methods for measuring electrical proper-

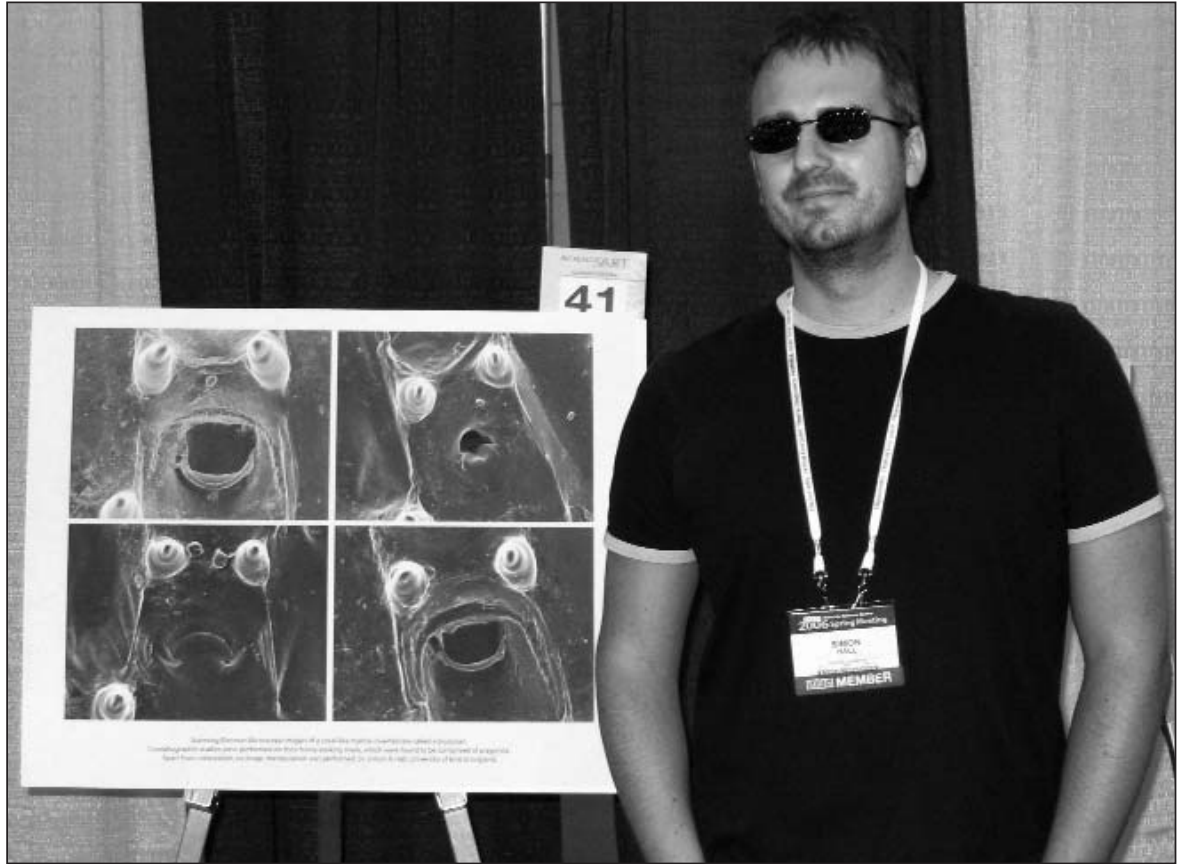

Simon R. Hall, University of Bristol, received one of the three first-place prizes in the second annual "Science as Art" competition, for "Bryozoans." Other first-place prizes went to Erik D. Spoerke and Bonnie McKenzie, Sandia National Laboratories, for "Toxic Garden," and to James V. Ly, University of Southern California, for "Polypyrrole Conducting Polymer Film." Second-place prizes went to Richard J. Wagner, National Institute of Standards and Technology, for "Calligraphy"; Brad Boyce and Richard Grant, Sandia National Laboratories, for "4340 Fracture Anaglyph"; and Raj Bhandari, University of Utah, for "Prismatic Folds." The entries were on display in the Moscone West Convention Center during the MRS Spring Meeting.

ties as well as advances such as the local electrode atom probe (LEAP) presented by J.S. Moore (Univ. of Florida, Gainesville) which was shown to produce $3 \mathrm{D}$ impurity composition and location information for SiGe superlattices.

\section{Challenges Addressed in CMOS Device Scaling}

\section{(See MRS Proceedings Volume 913)}

Symposium D on Transistor ScalingMethods, Materials, and Modeling reviewed various key issues in CMOS device scaling and addressed critical research challenges. The ITRS roadmap requirements and implications for new materials and techniques were delineated in the symposium tutorial. Highlights of the symposium covered topics such as the amorphization/templated recrystallization method for hybrid orientation substrates; CMOS scaling challenges; strain engineering and body biasing for optimization of sub-45-nm CMOS device performance; various strained-Si technologies for nano-CMOS devices; CMOS performance enhancement from a combination of NiSi metal gate and uniaxial strained Si channels; and key issues of TCAD modeling of strain-engineered MOSFETs.

Symposium Support: Taizwan Semiconductor Manufacturing Co. Ltd.

\section{Hf-Based Materials Remain Best} Candidates for First High- $\kappa$ Generation (See MRS Proceedings Volume 917E)

Symposium E on Gate Stack ScalingMaterials Selection, Role of Interfaces, and Reliability Implications left no doubt about Hf-based materials as the best candidates to be implemented in the first high- $\kappa$ generation; however, many issues are still open and its extendibility in further EOT reduction is uncertain. On the other hand, metals for gate electrode are still in a selection stage.

Several talks focused on reliability, a key issue of metal/high- $\kappa$ gate stacks. In particular, bias temperature instability characteristics were discussed with their interface structures and properties. Improvements with intentionally incorporated impurities, such as nitrogen (G. Bersuker, SEMATECH) or fluorine (K. Seo, Stanford) were presented. Unique physical characterization 
methods, such as noncontact CoronaKelvin metrology, extended x-ray absorption fine structure, attenuated total reflection Fourier transform infrared, and electron energy-loss spectroscopy/electron energy-loss near-edge structure, were proven to be powerful tools in the study of the gate stacks. A. Uedono (Univ. of Tsukuba; NIMS, Japan) applied the positron annihilation method to Hf-based high- $\kappa$ dielectrics to probe open volume in the film. From Doppler broadening spectra and lifetime spectra of positrons, the mean size of the open volumes and their size distribution changing with annealing and/or nitrogen incorporation were reported for $\mathrm{HfSiOx}$ and HfAlOx. Some progressive works done on Ge substrates as an alternative to Si and studies of non-Hf-based high- $\kappa$ gate dielectrics for next generations show continuous expansion of the knowledge in this field.

\section{Range of Materials and Technologies Presented in Next-Generation Nonvolatile Memories \\ (See MRS Proceedings Volume 933E)}

Symposium G on Science and Technology of Nonvolatile Memories featured sessions on flash memories, advanced nanocrystal-based gate-flash memories, FeRAM, resistive RAM, scanning probe memories, and phase-change memories, with a focus on materials science, materials integration, device architecture, and device physics. In addition, sessions included discussions on the development of new fabrication processes to produce nanostructures using either top-down (advanced conventional lithography) or bottom-up (self-assembly) approaches and new materials beyond silicon that will be required for the next generation of nonvolatile memories. The sessions revealed intensive investigation on materials currently not used in the microelectronics industry, which might find application in the new generation of nonvolatile memories. Among the nontraditional materials investigated were complex oxides (e.g., perovskite ferroelectrics and high- $\kappa$ dielectrics), magnetic thin films, chalcogenides, organics, and CNTs. The symposium provided information on synthesis of the new generation of materials in thin film and integration strategies and device architectures that will require a combination of film synthesis methods and in situ and ex situ characterization techniques and micro- and nanoscale fabrication processes capable of providing, in many cases, atomic-scale resolution for the development of nonvolatile memories.

Symposium Support: Samsung Advanced Institute of Technology.

\section{Nanoscale Informal Science Education (NISE) Activities Debut at Spring Meeting}

The 2006 MRS Spring Meeting was the first to play host to a set of activities to publicize the Nanoscale Informal Science Education (NISE) Network. The NISE project is a \$20 million NSF-funded outreach effort to help feed the national public discourse and understanding of nanotechnology. It is led by three leading science museums: the Museum of Science in Boston, the Exploratorium in San Francisco, and the Science Museum of Minnesota.

MRS has the lead responsibility for building a network of research scientists who will serve as subject-area experts for the science museums. These experts will review scientific content and provide technical oversight and advice on NISE projects and activities. They may also participate in the development of NISE products, such as tools for Informal Science Education (ISE) training.

The focus of NISE during the first two years of the project will be on developing the best approaches to engaging public audiences in understanding and discussing nanoscale science and engineering themes and perspectives. This will be accomplished through the development of a wide variety of prototype exhibits, programs, media, and professional development activities. The focus during subsequent years will be on the production, implementation, and dissemination of educational and professional development activities and materials.

At the Spring Meeting, NISE activities were located near the other MRS outreach venues and included:

- The Visualization Lab area, led by an Exploratorium team, where scientific artists brainstormed with MRS meeting attendees to develop visual renderings of nanoscale landscapes;

- Exhibit prototype elements from the Exploratorium, the Oregon Museum of Science \& Industry, Children's Museum of Houston, and the MRSEC at the University of Wisconsin, Madison;

- A video on the NISE Network and ISE produced by the Science Museum of Minnesota; and

- Various opportunities to sign up to get involved.

In addition, presentations about the NISE network were given as part of Symposium KK on materials education, at the University Chapters luncheon, and immediately following the NSF funding seminar. For more information, access Web site www.mrs.org/nise_survey.

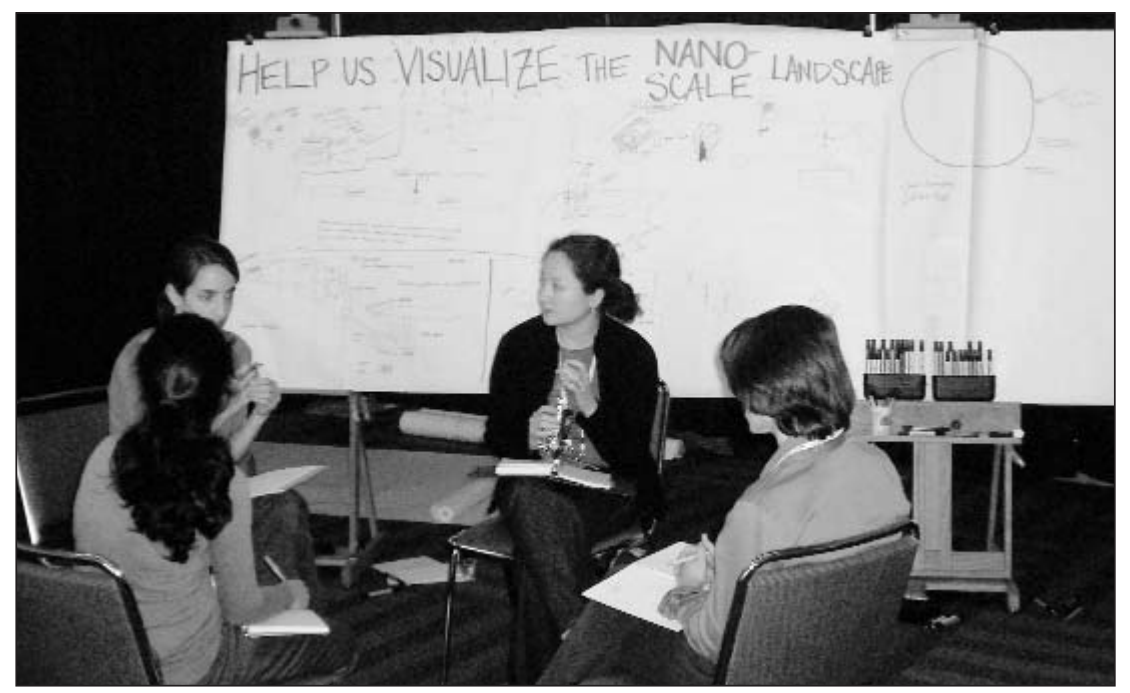

To assist in the NSF-funded Nanoscale Informal Science Education (NISE) project, attendees at the 2006 MRS Spring Meeting examined and commented on prototype exhibits. The attendees were invited to "help visualize the nanoscale landscape" by brainstorming with artists and illustrators to "see" into the nanoworld. The NISE effort is intended to foster public awareness of, engagement in, and understanding of nanoscale science, engineering, and technology. MRS is playing a major role in the NISE network, linking scientists with informal science education projects. 


\section{$\mathrm{Ge}_{2} \mathrm{Sb}_{2} \mathrm{Te}_{5}$ Most Prominent Alloy in Studies on Chalcogenide-Based Phase-Change Materials}

(See MRS Proceedings Volume 918E)

Symposium $\mathrm{H}$ focused on a fairly restricted class of materials: alloys containing chalcogen atoms $(\mathrm{S}, \mathrm{Se}, \mathrm{Te})$ that undergo very rapid phase transitions under the influence of either electrical or optical excitation. The alloy of greatest current interest is $\mathrm{Ge}_{2} \mathrm{Sb}_{2} \mathrm{Te}_{5}$. However, many other materials were also represented in this symposium on Chalcogenide-Based Phase-Change Materials for Reconfigurable Electronics.

The most contentious single area of study was the structure of the amorphous state of $\mathrm{Ge}_{2} \mathrm{Sb}_{2} \mathrm{Te}_{5}$. There were also several areas where separate presentations provided complementary insights. J. Chelikowsky (Univ. of Texas, Austin) gave an invited presentation on theoretical studies of liquid GeTe wherein the liquid retains important features of the crystalline state. G. Wicker (Ovonyx Inc., Mich.) presented data that showed liquid $\mathrm{Ge}_{2} \mathrm{Sb}_{2} \mathrm{Te}_{5}$ has resistivity that is continuous with the hcp crystal, while the resistivity for the amorphous phase was much higher. This seems to imply that the liquid has more in common with the crystal. E. Lee (Samsung Advanced Inst. of Technology, South Korea) presented results for memory based on nanoparticles of $\mathrm{Ge}_{2} \mathrm{Sb}_{2} \mathrm{Te}_{5}$. After melting, these nanoparticles apparently retained their identity. T.-Y. Lee (Seoul Natl. Univ.) showed that when $\mathrm{Ge}_{2} \mathrm{Sb}_{2} \mathrm{Te}_{5}$ is codeposited with $\mathrm{SiO}_{2}$, the material phase apparently separates on a fine scale, forming $\mathrm{Ge}_{2} \mathrm{Sb}_{2} \mathrm{Te}_{5}$ inclusions surrounded by $\mathrm{SiO}_{2}$. Y.W. Park (Seoul Natl. Univ.) presented modeling suggesting that a structure layered with similar nanoparticles of $\mathrm{Ge}_{2} \mathrm{Sb}_{2} \mathrm{Te}_{5}$ could allow for multilevel data storage. H.-G. Jun (Seoul Natl. Univ.) showed measured data from a simple layered structure allowing for three resistance levels instead of the standard two.

The research uncovered in this symposium highlighted the importance of looking at trends in materials. In F. Houle's (IBM Almaden Research Ctr.) discussion of thin films of nominal $\mathrm{Ge}_{2} \mathrm{Sb}_{2} \mathrm{Te}_{5}$, SIMS showed that there was essentially no bulk region exhibiting that stoichiometry. Thus, any mechanism for phase transition must be robust. M.G. Kanatzidis (Michigan State Univ.) gave an invited talk on mixed ionic-covalent chalcogenide materials that exhibit a striking variety of phase transitions. Talks showing the effects of $\mathrm{Sn}$ and Bi replacing Ge and $\mathrm{Sb}$ revealed that the heavier atoms led to complete inhibition of glass formation. Talks also showed the effects of $\mathrm{Si}$ replacing Ge. S. Raoux (IBM Almaden Research Ctr.) discussed the group's work on GeSb (no chalcogens at all) and its relationship to $\mathrm{Ge}_{2} \mathrm{Sb}_{2} \mathrm{Te}_{5}$ and to AIST (Ag-In-Sb-Te alloys) that illuminated the varied behavior of nucleation between the GST and AIST materials. At the same time, the GeSb work had possible practical implications. It displayed very low resistance in the $\mathrm{ON}$ state and a very large dynamic range, making it a potential candidate for use in reconfigurable interconnects and, hence, hardwareprogrammable gate arrays.

\section{Si Microphotonics Blends with Silicon Electronics}

(See MRS Proceedings Volume 934E)

Symposium I on Silicon-Based Microphotonics addressed the fusion of Si IC technology with photonics to usher in the next generation of information processing technology and infrastructure based on monolithically integrated optoelectronic components. To this end, many novel materials and device structures that can emit, modulate, and detect light signals and are compatible with Si CMOS technology were investigated. For light-emitting materials, Si nanostructures and rare-earth doping attracted particular attention, and T. Kippenberg (Caltech) demonstrated how these materials, in combination with an ultrahigh-Q microcavity fabricated using CMOS-compatible procedures, can be used to manufacture lasers on a chip. J. Harris (Stanford) demonstrated how III-V expertise can be transferred to $\mathrm{Si}$ to realize ultrafast broadband optical modulators based on SiGe superlattices. Use of plasmon resonance to control and enhance light emission from $\mathrm{Si}$ nanostructures also drew wide interest. P. Fauchet (Univ. of Rochester) and L. Kimerling (MIT) presented an overview and roadmap showing how the development of Si microphotonics technology is necessary to overcome the impending "interconnect bottleneck" of IC technology.

\section{Positive Future Seen for Negative- Index Materials \\ (See MRS Proceedings Volume 919E)}

Because of the unusual electromagnetic properties resulting from the negative index of refraction associated with negative-index materials, their successful validation has led to a variety of proposals for new components. In Symposium J on NegativeIndex Materials-From Microwave to Optical, developments in metamaterials physics, fabrication methodologies, imaging innovation, and new applications in microwave to optical wavelengths were discussed. Microwave metamaterials and components are quickly emerging from concepts to devices. G. Eleftheriades (Univ. of Toronto) and colleagues used transmission-line metamaterials, experimentally probed negative refraction, and focused phenomena at microwave frequencies. E. Ozbay (Bilkent Univ., Turkey) and co-workers examined the collimation effect and imaging resolution on a set of metallic metamaterials and photonic crystals up to $100 \mathrm{GHz}$. Their findings and many other presentations revealed key insights into the slow wave and the critical surface resonance characteristics of the negative refraction.

Experimental results of the negativeindex materials at visible to infrared wavelengths captured intense discussion among the participants. Achieving a negative refractive index with low losses at optical frequencies still remains to be solved. V. Shalaev (Purdue) introduced a design of paired nanowires with a set of experiments confirming the negative index at optical wavelength. An extensive numerical study of a possible route to negative permeability and subwavelength imaging in the visible wavelength was described by S. Kawata and colleagues from RIKEN and Osaka University in Japan, while M. Qiu (Royal Inst. of Technology, Sweden) and colleagues presented the experimental observation of negative refraction and superprism effects inside photonic crystals and the potential applications in telecommunication components. $\mathrm{W}$. Wu (HP) concluded by the end of the symposium, "The future is very positive for negative-index materials."

\section{Materials Properties, Devices, and Characterization Methods Discussed for THz Spectral Range}

(See MRS Proceedings Volume 935E)

Spectroscopy in the $\mathrm{THz}$ frequency range has grown into an established research field that helps answering important questions in physics, chemistry, and biology. Relatively unexplored in the past, the $\mathrm{THz}$ region became more accessible with the introduction of ultrafast lasers. Now $\mathrm{THz}$ spectroscopy opens new possibilities for materials characterization, as revealed in Symposium K on Materials Research for $\mathrm{THz}$ Applications. R. Kaindl (LBNL) discussed semiconductor exciton systems, where internal exciton transitions occur in the $\mathrm{THz}$ range, and $\mathrm{R}$. Huber (UC-Berkeley) demonstrated stimulated emission of $\mathrm{THz}$ waves from excitons in $\mathrm{Cu}_{2} \mathrm{O}$. P. Taday (Teraview) showed that different crystalline phases of a variety of biological materials used in the pharmaceutical industry can be identified by their $\mathrm{THz}$ spectral signatures. In the area of $\mathrm{THz}$ 
applications, S. Barberi (Teraview) and Q. Hu (MIT) reviewed recent advances in the field of $\mathrm{THz}$ quantum cascade lasers and demonstrated long-wavelength devices with operating temperatures above $100 \mathrm{~K}$. Furthermore, Hu demonstrated real-time T-ray imaging using a quantum cascade laser as a source. A. Bartels (Univ. of Konstanz) demonstrated a compact high-resolution $\mathrm{THz}$ sampling spectrometer based on two synchronized pulsed lasers.

Symposium Support: LANL and SNL.

\section{Flexible Substrates and OLED Devices Figure Prominently in Next-Generation Display Technologies}

(See MRS Proceedings Volume 936E)

Symposium L on Materials for NextGeneration Display Systems, a forum for emerging displays, dealt largely with frontplane and backplane technologies, new materials, and new processes for display fabrication. Y. Kijima (Sony) described the company's "super top emission" OLED architecture in detail and disclosed a new color-by-white version. The use of microcavities provides good color and eliminates the need for circular polarizers. T.-H. Kwon (Seoul Natl. Univ.) presented the concept of "hopants," or dopant species chemically bound to host molecules, which gave high-efficiency phosphorescent OLEDs. S. Lamansky (3M) described the company's laser-induced thermal imaging (LITI) process which may be used to pattern a wide variety of OLED materials at very high resolution. Device lifetimes and advantages of the LITI process over fine metal mask, and inkjet printing were addressed. J. Kido (Yamagata Univ.) discussed high-efficiency white OLEDs based on Ir emitters. When light out-coupling films were placed on the devices, luminous efficiencies of $63 \mathrm{~lm} / \mathrm{W}$ were obtained. Kido predicted efficiencies of $100 \mathrm{~lm} / \mathrm{W}$ for the near future.

S. Dunn (Cranfield Univ.) showed that CdTe quantum dots could be sandwiched between ITO and Al electrodes to give planar EL devices that performed similarly to OLEDs. The quantum dots can be inkjet-printed and the devices showed good shelf stability.

E. Fortunato (Univ. of New Lisbon) presented transparent TFTs based mainly on IZO. The entire TFT structure, gate, insulator, semiconductor, and source and drain are $80 \%$ transparent in the visible range. This may provide a new solution to aperture ratio issues. T. Someya (Univ. of Tokyo) discussed a variety of flexible TFT devices including a 32-in.-diagonal backplane for a pressure sensor array. T. Jackson (PSU) described extensive work on flexible pentacene TFTs and cited the potential for low-cost fabrication as the most significant reason to pursue flexible devices.

\section{Advances Seen in Organic Conjugated Materials and Devices}

(See MRS Proceedings Volume 937E)

Symposium M on Conjugated Organic Materials-Synthesis, Structure, Device, and Applications opened with talks describing the synthesis and design of novel organic materials, from electroactive star-shaped molecules (M. Galvin, Air Products), to nano/microwires, to materials useful for sensors. In the area of organic semiconducting devices, presentations addressed charge transport through $\pi$-conjugated materials (J-L.E. Bredas, Georgia Tech), at interfaces (H. Sirringhaus, Cavendish $\mathrm{Lab}$ ), and in polycrystalline polymer TFTs (B. Street, PARC). D. DeLongchamp (NIST) presented morphology from a high-mobility polymer semiconductor recently reported by Merck $\left(0.6 \mathrm{~cm}^{2} / \mathrm{V} \mathrm{s}\right)$. A highlight of organic semiconductor materials that rival a-Si performance was given by J. Veres (Merck Chemicals). A.L. Briseno (UCLA and Stanford) reported a method to grow large arrays of single crystals of rubrene and pentacene with mobility as high as $2.3 \mathrm{~cm}^{2} / \mathrm{V}$ s and greater than $10^{6} \mathrm{on} / \mathrm{off}$ ratio. The promise of organic transistors in ICs and active-matrix displays was described by G. Gelinck (Polymer Vision), who said that rollable displays based on electrophoretic ink would be available commercially in the first half of 2007. S. Steudel (IMEC, Katholieke Univ., Leuven) reported a Schottky-type rectifier from a Au-pentacene-Al stack with $10 \mathrm{~V}$ output from a $20 \mathrm{~V}$ input signal for use in organic RFID tags. The promise of organic LEDs in solid-state lighting was described by S. Forrest (Univ. of Michigan), who announced the achievement of an approximately $25 \mathrm{~lm} / \mathrm{W}$ white OLED with a high color rendering index of $\sim 85$ based on a combination of fluorescent blue and phosphorescent red and green emitters. An unusual aspect of this design is the ability to obtain $100 \%$ IQE even though a fluorescent blue is employed. The symposium concluded with molecular level and thinfilm studies, where D. Carroll (Wake Forest Univ.) reported on an external quantum efficiency of $7 \%$ for a polythiophene $/ \mathrm{C}_{60}$-based solar cell.

Symposium Support: Eastman Kodak Co., GE Global Research, NSF, and University Display Corp.

\section{Diversity of Optoelectronic Devices Emphasized in Merger of Inorganic and Organic Hybrid Materials}

(See MRS Proceedings Volume 939E)

The overall aim of Symposium $\mathrm{O}$, Hybrid Organic/Inorganic/Metallic Elec- tronic and Optical Devices, was to bring together researchers working with hybrid materials systems on the various applications in which they are potentially useful. The opening session on photovoltaic research brought together a broad range of materials approaches to efficiently and effectively convert solar energy into usable power. M. Baldo (MIT) explained his novel external organic antenna approach to increase the light absorption possible within a high-efficiency thin-film cell. N. Greenham (Univ. of Cambridge) and T. Sargent (Univ. of Toronto) expanded on understanding the structure-performance relationship within inorganic nanomaterials (quantum dots and nanorods) and polymer-blend PV cells. M. McGehee (Stanford) and M. Graetzel (Ecole Polytechnique de Lausanne) both discussed the importance of understanding organicinorganic interfaces in optimizing solar cell performance.

In the following sessions, C. Scott and L. Bozano from IBM Almaden Research Center, and S. Carter (UCSC) each presented works that bridged the gap between computer simulation and experimental devices, leading toward a superior understanding of how nanoparticles of metal behave within dielectric media under working conditions within a device. Scott's results could be seen to have immediate impact on the devices presented by Bozano in a later session. A series of talks by J. Steckel (MIT), S. Forrest (Univ. of Michigan), V. Klimov (LANL), and Y. Yang (UCLA) gave updates on the status of hybrid organic-inorganic memory cells and LEDs, each using very different device structures. The diversity of approaches gave the audience a very broad sense of the possibilities inherent in hybrid material sets, the known challenges, and their limitations.

\section{$\mathrm{Si}, \mathrm{Ge}$, III-V, and II-VI Explored for Semiconductor Wires}

(See MRS Proceedings Volume 940E)

Symposium P on Semiconductor Nanowires-Fabrication, Physical Properties, and Applications opened with a lecture by U. Gösele (MPI, Halle) who pointed out the importance of understanding how to define size, position, and structure of the wires before a device can be fabricated based on such nanowires. The use of ultrahigh-vacuum transmission electron microscopy to grow $\langle 111\rangle$-oriented Si wires was shown in real time-in the presence of molten Au-Si eutectic droplets serving as the catalysts-that provided insights into mechanisms governing the kinetics of Si nanowire growth (F.M. Ross, IBM, Yorktown Heights). A number of 

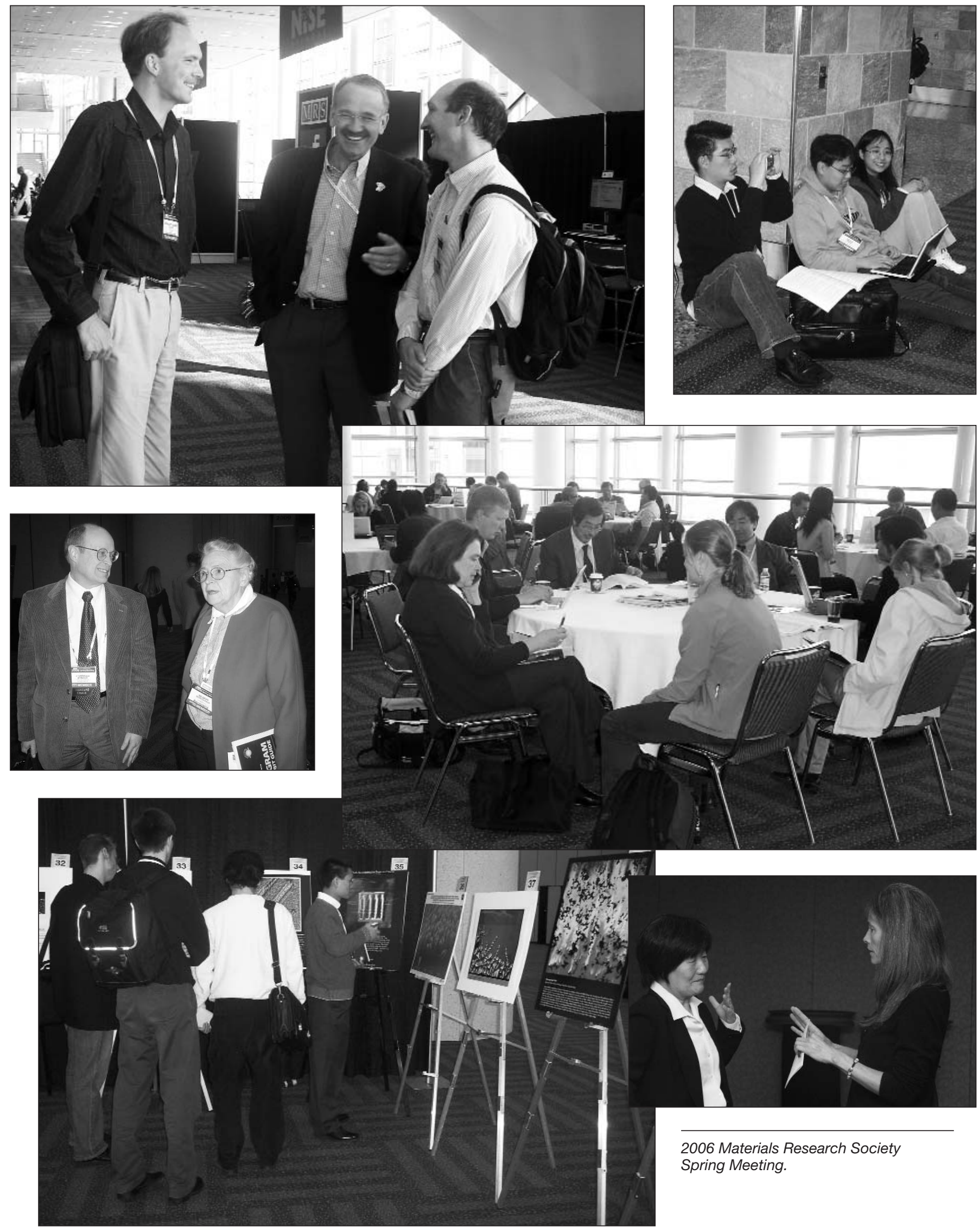

2006 Materials Research Society

Spring Meeting. 
talks demonstrated recent developments in understanding the transport behavior (S. De Franceschi, Delft Univ.) and investigations of various kinds of nanowirebased devices (L. Samuelson, Lund Univ.). The results revealed key insights on transport behavior and emphasized the critical role of interfaces and electrical contacts.

$\mathrm{ZnO}$ and related materials are of interest for optical and sensor applications and exhibit interesting piezoelectric properties (Z.L. Wang, Georgia Tech). A.P. Alivisatos (UC-Berkeley) demonstrated the control of complex shapes and topologies by colloidal synthesis. Detailed investigations of the photoluminescent properties and FETs based on heterostructures and core-shell structures based on $\mathrm{ZnO}$ were shown by G.-C. Yi (POSTECH, Pohang, Korea).

Symposium Support: First Nano Inc. and IBM Zurich $\mathrm{GmbH}$.

\section{Experimental and Theoretical Developments Demonstrated for Magnetic Thin-Film Device Materials (See MRS Proceedings Volume 941E)}

In Symposium $Q$ on Magnetic Thin Films, Heterostructures, and Device Materials, spin-dependent tunneling junctions were presented, with a particular focus on $\mathrm{Fe} / \mathrm{MgO} / \mathrm{Fe}$ junctions. Tunneling magnetoresistance values in this system have recently attained up to $350 \%$ at room temperature, several times higher than those seen in any other materials system. High magnetoresistance values were presented experimentally, treated through $a b$ initio models, and correlated with $\mathrm{MgO}$ barrier structure by in situ STM and XPS characterization. Prospects for incorporation into nonvolatile magnetic RAM devices were also reviewed. Among other highlights were possibilities for novel interactions of ferromagnetic layers with other functional material types; novel rectifying possibilities, predicted theoretically, for the integration of ferroelectrics such as $\mathrm{SrTiO}_{3}$, in the tunnel barrier between metallic Co electrodes; unambiguous proof of electrical injection and detection of spinpolarized electrons from metallic ferromagnets through GaAs, through the Hanle effect; and all-oxide magnetic tunneling junctions based on $\mathrm{NiMn}_{2} \mathrm{O}_{4}$ barriers. Materials approaches to increasing subnanosecond switching speeds, critical for high-data-rate $(>1 \mathrm{GHz})$ information storage, were presented. It was shown that the damping constant for high-speed motion can be predicted from first principles only in layered structures; controlled in epitaxial Fe alloys, potentially reduced below the intrinsic value of pure Fe; correlated with the femtosecond demagnetization process; and understood microscopically through picosecond-scale time-resolved $\mathrm{x}$-ray spectroscopy. Composition spread approaches for the discovery of high-frequency magnetic materials were also reviewed.
The complex reversal process in submicrometer patterned elements could be understood using magnetic force microscopy and magnetoresistance measure-

\section{Graduate Students Receive Gold and Silver Awards}

Graduate Student Awards were announced during an evening ceremony on April 19 at the 2006 Materials Research Society Spring Meeting in San Francisco.

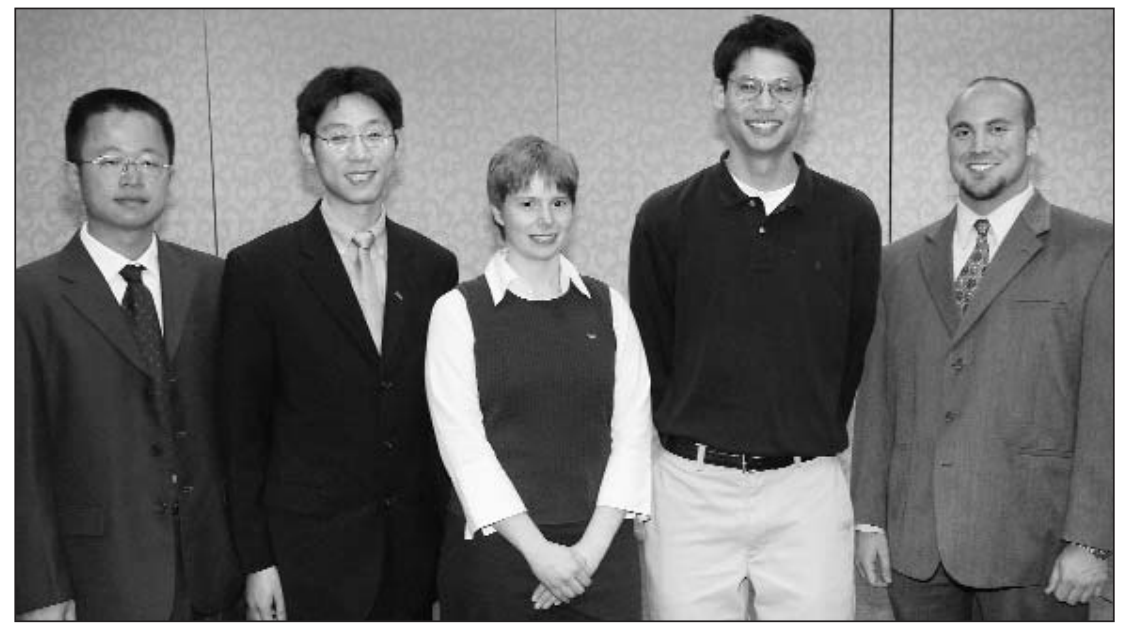

Gold Graduate Student Awards were awarded to (left to right) Gengfeng Zheng (Harvard University), Rong Fan (University of California, Berkeley), Jana Zaumseil (University of Cambridge), Emory M. Chan (University of California, Berkeley), and Lane W. Martin (University of California, Berkeley).

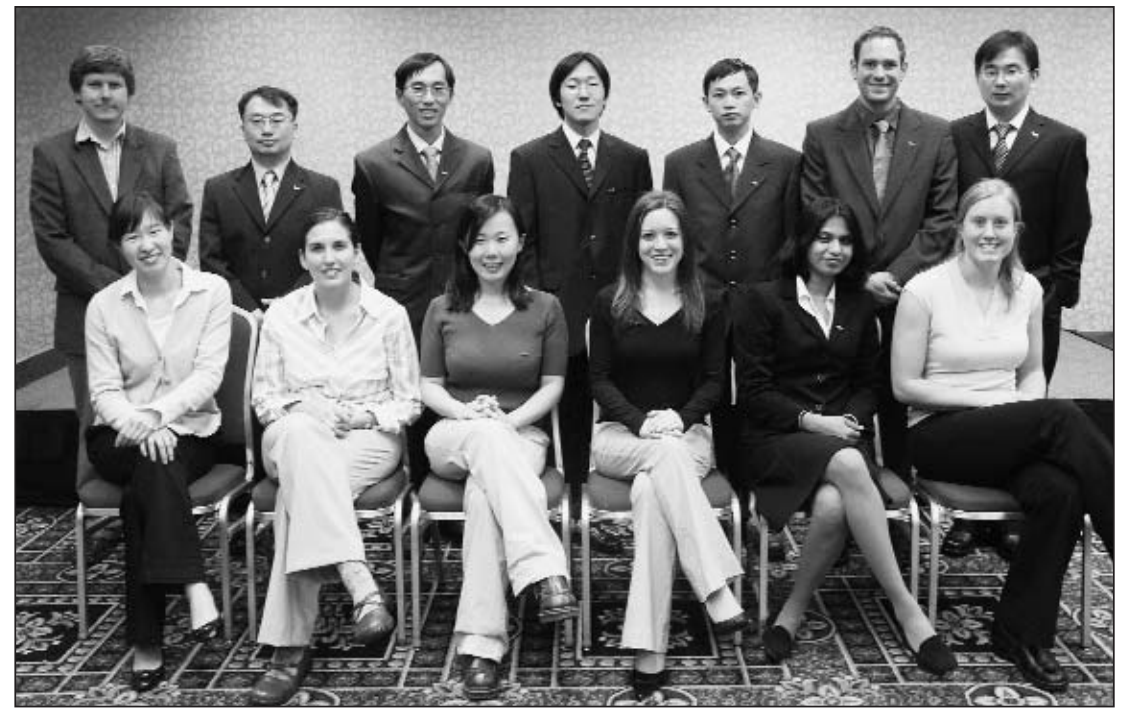

Silver Graduate Student Awards were awarded to (front row, left to right) Andrea R. Tao (University of California, Berkeley), Christine E. Richardson (California Institute of Technology), Arum A. Yu (Massachusetts Institute of Technology), Julia Deneen (University of Minnesota), Rashmi Jha (North Carolina State University), and Lori E. Greene (University of California, Berkeley); (back row, left to right) Robert J. Walters (California Institute of Technology), Czang-Ho Lee (University of Waterloo), Chung-Yi Chiang (Massachusetts Institute of

Technology), Yunseok Kim (Korea Advanced Institute of Science and

Technology), Yongfeng Guan (Columbia University), Liam S.C. Pingree (Northwestern University), and Lidong Qin (Northwestern University). 
ments and detailed studies of hysteresis loops. Novel results were shown on multiferroic materials, in which close coupling of charge (ferroelectric) and magnetic (antiferromagnetic) ordering is predicted. Some initial evidence for the reciprocal influence of FE domains on AF domains in $\mathrm{BiFeO}_{3}$ were presented through linear dichroism in PEEM and through hysteresis loops in $\mathrm{YMnO}_{3}$.

Symposium Support: ARL, ONR, and Samsung Advanced Institute of Technology.

\section{New Trends Covered in Nanostructures and Hybrid Composites for Gas Sensors and Biomedical Applications} (See MRS Proceedings Volume 915)

Symposium R on Nanostructured Materials and Hybrid Composites for Gas Sensors and Biomedical Applications covered new trends with bio-hybrid materials (B. Dunn, UCLA) and intercalative organic and metal oxides (I. Matsumara, AIST) and spanned over a new generation of materials, such as nanowires, both in terms of first principles (A. Kolmakov, SIUC), growth, and production (Z.L. Wang, Georgia Univ.), and their implementation to gas sensing even to the extreme of singlewire detection (J.R. Morante, Barcelona Univ.).

Among multi-parametric pattern recognition methods, colorimetric sensor arrays deserve special attention because of their capability in monitoring toxic chemicals (K. Suslick, UIUC). Very fine nanometric particles and excellent control over the dimensionality proved possible through deposition from an aerosol phase (N. Barsan, Tübingen Univ.).

Hydrogen sensing was also addressed with success through either titania nanotubes (C.A. Grimes, PSU) or a mixed tin titanium oxide solid solution (M.C. Carotta, Ferrara Univ.).

Symposium Support: Dipartimento di Fisica, Universitá di Ferrara.

\section{Advances in Smart NanoTextiles Add Function to Clothing \\ (See MRS Proceedings Volume 920)}

Innovations in the nanoscale manipulation of fibers and textiles have created a new momentum in designing functional garments and clothes to be used for personal mobility, healthcare, or rehabilitation. Symposium S on Smart NanoTextiles addressed new materials and fibers, sensing, and applications.

Examples of extended functionality of fibers include conducting polymer fibers (B.R. Mattes, Santa Fe Science and Technology Inc.), enhanced strain sensitivity fibers obtained by chemically polymeriz- ing PPy (X. Tao, Hong Kong Polytechnic Univ.), and piezoelectric and ferroelectric properties by applying ultrafine vinylidene fluoride nanofibers in an electrospinning process ( $\mathrm{Y}$. Dzenis, Univ. of Nebraska, Lincoln). Some talks captured recent developments in shape-memory fibers, such as using triblock liquid-crystal polymers (S. Ahir, Univ. of Cambridge) or polyurethane-CNT composites.

The benefit of CNTs was also investigated by S.S. Rhahatekar (Univ. of Cambridge), who presented CNT-filled thermoplastic polymer textile fibers, and $\mathrm{R}$. Baughman (Univ. of Texas, Dallas) who focused on methods for producing polymer-free CNT yarns and transparent sheets.

Inspired by nature, research groups have mimicked biological archetypes to improve the behavior of fibers. The group of Z. Guan (UC-Irvine) used the skeletal muscle protein titin as a model to develop modular multidomain polymers. C.-Y. Chiang (MIT) and colleagues examined how to incorporate the M13 bacteriophage for the design of a virus-based nanoarchitecture including nanowires.

Nanoparticle-coated fibers can enhance wearing comfort, as reported by $\mathrm{Z}$. $\mathrm{Hu}$ (Hong Kong Polytechnic Univ.) and colleagues, who introduced a stable silver oxide suspension in chitosan that contains silver oxide nanoparticles of $10-20 \mathrm{~nm}$ on average. Cotton fabrics treated with this emulsion have shown significant antibacterial activity. Furthermore, in cotton, selfcleaning behavior can be improved by applying a nanocrystalline anatase titanium dioxide film from an alkoxide solution using a low-temperature sol-gel process.
In the area of inkjet printing of textiles, A. Sawhney (Univ. of Massachusetts) and colleagues reported on their printed arrays of strain sensors consisting of conducting lines and a piezoresistive polymer (PEDOT).

\section{Approaches to Scalable, Low-Cost Nanoscale Fabrication Highlighted (See MRS Proceedings Volume 921E)}

Symposium $\mathrm{T}$ on Nanomanufacturing brought together researchers from diverse areas to highlight advances being made in the formation of functional nanostructures and approaches for the patterned organization of such structures over large areas with nanoscale precision.

While manufacturing complex devices on the nanoscale is now having an impact on consumer electronic markets with the mass production of computer chips with linewidths of $65 \mathrm{~nm}$, research on alternative means for nanomanufacturing offers pathways to future nanofabrication technology with smaller features and lowercost production methods. In Symposium $\mathrm{T}$, scalable capabilities for the formation of features of $<65 \mathrm{~nm}$ and 3D fabrication were highlighted in several talks. R.S. Williams (HP) said that linewidths and spacings down to $17 \mathrm{~nm}$ have been obtained and integrated into a 16 Kbyte memory elements by nanoimprint lithography and that a path toward linewidths and spacings down to $4 \mathrm{~nm}$ is foreseeable; methods to allow defect tolerance are necessary for future-generation nanodevices. T. Makela (VTT) showed that nanoimprint lithography can be extended to roll-to-roll processes where 100-nm-wide features were pat-

\section{Materials Research Priorities Revealed at Government Funding Seminars}

The materials research community is experiencing worldwide interest in nanotechnology among other priorities from government funding agencies. MarieIsabelle Baraton (Université de Limoges, France) discussed the priority area of nanotechnology within the European Union's 6th Framework Programme, and Hideomi Koinuma, vice president of the National Institute for Materials Science in Tsukuba, Japan, described the nanotechnology landscape in Japan, including the Nanotechnology Researchers Network Center (Nanonet). W. Lance Haworth, acting director of the Division of Materials Research at NSF, said that the nanotechnology initiative will remain a major focus for NSF but that several new programs are on the horizon, such as a biomaterials program. This program is designed to foster the study of bio-related materials and phenomena, including the investigation of biological pathways to new materials.

Harriet Kung, director of the Division of Materials Sciences and Engineering within the Office of Basic Energy Sciences at DOE, described the four solicitations planned for fiscal year 2007, including midscale instrumentation, solar energy conversion, hydrogen, and nuclear research.

In addition to the presentations on government funding, the National Academies held a Town Hall Meeting on Condensed Matter and Materials Physics (CMMP 2010) in order to get input from the MRS community of materials researchers for the next decadal study of the field of CMMP. 
terned on the entire $50 \mathrm{~mm}$ width of a web and should be extendable to $2 \mathrm{~m}$ width of a web and may enable the fabrication of organic electronic devices, including flexible displays. H.I. Smith (MIT) described the use of focusing diffractive optic arrays and a programmable deformable mirror array for rapid, programmable, large-area, direct-laser-writing of 2D structures with nanoscale registration of written features. S. Kawata (Osaka Univ. and RIKEN) described the direct laser writing of largearea arrays of helices by multiphoton lithography using a scanning laser and a microlens array and their metallization as a possible route to metamaterials.

Functional electronic and optoelectronic devices enabled by nanomaterials were highlighted by several speakers. P. Avouris (IBM) presented results on the integration of CNTs by patterned chemically affinity to form light-emitters and a five-stage ring oscillator. P. Yang (UC-Berkeley) described the combination of subwavelength photonic nanowire waveguides with silver nanocubes for sensing applications.

Symposium Support: HP.

\section{Device Applications and Complex} Hierarchical and Composite Materials Serve as Trends in Nanotube Research (See MRS Proceedings Volume 922E)

In Symposium U on Organic and Inorganic Nanotubes-From Molecular to Submicron Structures, S.I. Stupp (Northwestern) discussed the need to develop "codes" to control the shape and function of 1D nanostructures. Such structures are important because they can be used to connect points by self-assembly, they may align in external fields, and they can form fibrils and networks to mimic biological extracellular matrices. One such code that Stupp's group developed is for helix formation. Helices occur extensively in nature over a range of scales, from DNA strands down to viruses, and learning to control the properties of self-assembled helices is a necessary step in biomimetic engineering. Stupp and his group control the pitch of a helix by controlling the torque on a molecular cylinder through the addition of chemical substituents to amphiphiles. Starting with a peptide lipid cylinder, they substituted increasingly bulky organic functional groups for hydrogen atoms. These substituents create steric hindrance, and the axis of the cylinder coils to minimize elastic energy. Using benzophenone as a terminal substituent, the researchers produced a helix with a pitch of $90 \mathrm{~nm}$. Adding another methyl group to the benzophenone reduced the pitch to $60 \mathrm{~nm}$ - a tighter spi- ral. Stupp showed how his group could produce helices with pitches from $160 \mathrm{~nm}$ down to $24 \mathrm{~nm}$ by judicious choice of bulky organic groups.

Among the many highlights of this symposium were reports on the potential application of inorganic nanotubes for biosensors and in semiconductor devices; template-based synthesis approaches of oxide and metal nanotubes; non-carbonbased organic nanotubes along with peptide, supramolecular, self-assembled lipid, and polymeric nanotubes; in-flight length classification of aerosol-grown CNTs; the epitaxial organization of CNTs; CNT FETs; and novel applications of CNTs close to commercialization, such as for ultrafast photonics (A.G. Rozhin,
Univ. of Cambridge) and membrane science (B.J. Hinds, Univ. of Kentucky).

S. Iijima (Meijo Univ., Japan) gave the symposium's keynote talk, "Recent Development of Carbon Nanotechnology," particularly highlighting the promising future application of CNTs for charge storage media.

Symposium Support: AIXTRON Inc.

\section{Measurement, Synthesis, and Assembly Highlighted for Charged Macromolecules at Solid-Liquid Interfaces}

(See MRS Proceedings Volume 923E)

In Symposium V on Structure and Dynamics of Charged Macromolecules at Solid-Liquid Interfaces, DNA microarray

\section{Poster Prizes Awarded at the 2006 MRS Spring Meeting}

The 2006 MRS Spring Meeting Chairs awarded prizes for the best poster presentations. Prize recipients received $\$ 500$, a certificate, and the honor of having their posters on display for the remainder of the meeting. Posters and authors awarded prizes were (E5.21) Electron Spin Resonance and Spin Dependent Recombination Studies of Silicon Dangling Bond Centers in Hafnium Oxide MOS Structures, J.T. Ryan, P. Lenahan, T. Pribicko, and J. Campbell (PSU); G. Bersuker, P. Lysaght, and S.C. Song (SEMATECH); and W. Tsai (Intel); (O3.23) Photoresponsive Sol-Gel Derived Hybrid Materials, L. Zhao and K.J. Shea (UC-Irvine), M. Vaupel (Nanofilm Technologie, Göttingen), and D.A. Loy (Univ. of Arizona); (P8.23) Electronic Interface Between Nanowires and Neurons, B.P. Timko, F. Patolsky, G. Yu, A.B. Greytak, and C.M. Lieber (Harvard Univ.); (P8.27) Strained Silicon Nanowire Field Effect Transistors by Bottom-up Device Integration, R. He, A. San Paulo, D. Gao, C. Carraro, R. Maboudian, J. Bokor, and P. Yang (UC-Berkeley); (P13.26) Fabrication and Photoluminescence Properties of Heteroepitaxial $\mathrm{ZnO} / \mathrm{Mg}_{0.2} \mathbf{Z n}_{0.80}$ Coaxial Nanorod Heterostructures, J. Yoo, W. Park, D.-W. Kim, and G.-C. Yi (POSTECH, South Korea), and M. Kim (Seoul Natl. Univ.); (U7.36) Integration of Single-Walled Carbon Nanotubes with III-V(110) Surfaces, L. Ruppalt and J.W. Lyding (UIUC); (Z3.10) Transmission Electron Microscopy Study of the Mechanical Behavior of Nanoscale Materials, J. Deneen, W.M. Mook, W.W. Gerberich, and C.B. Carter (Univ. of Minnesota), and A.M. Minor (LBNL); (Z8.14) Parallel Nano-Differential Scanning Calorimetry: A New Device for Combinatorial Analysis of Complex Nano-Scale Material Systems, P. McCluskey and J.J. Vlassak (Harvard Univ.); and (AA4.5) Biologically Directed Nanoscale Materials Assembly, E.D. Spoerke, G.D. Bachand, B.C. Bunker, J. Liu, C.E. Warrender, A.M. Bouchard, and G.C. Osbourn (SNL).

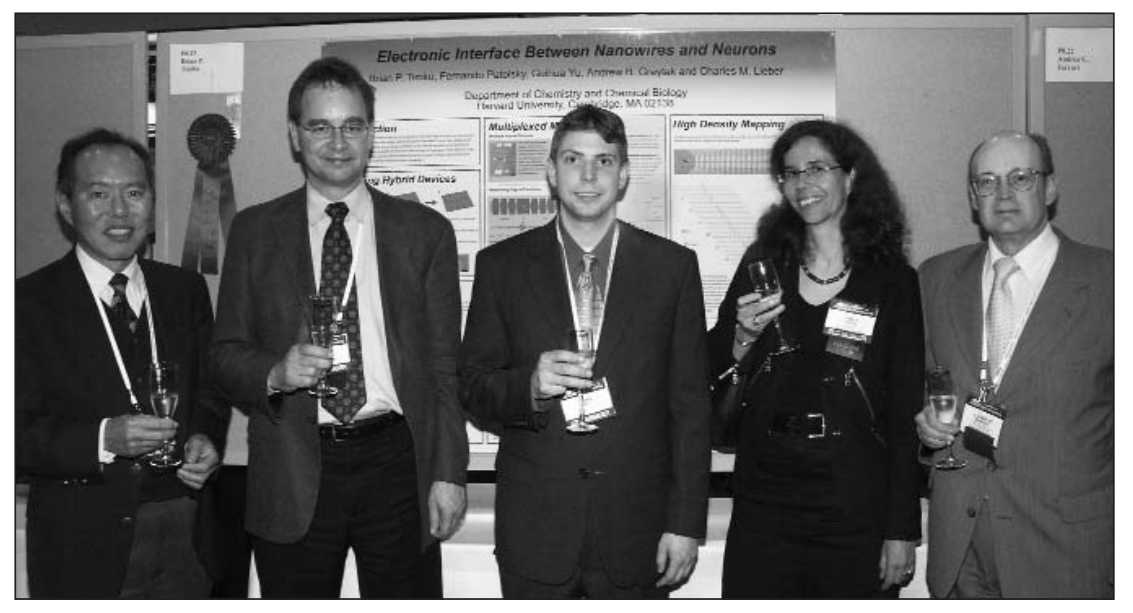


fundamentals were highlighted by R. Levicky (Columbia) to quantify the kinetics and thermodynamics of hybridization, observing that solution-phase hybridization is significantly different from solid-phase hybridization. This view was complemented by other research on molecular dynamics studies and core-shell microarray strategies. On the topic of polyelectrolyte multilayers, W. Knoll (MPI, Mainz) presented a com- prehensive picture of assembly using dendrimers to form layers and hollow tubes as well as capsules using welldefined, oppositely charged dendrimers with controlled functionality. This was complemented by the mechanism of layer-by-layer assembly achieved by other research groups.

A session on conformation and dynamics of single molecules brought together several cross-discipline measurement techniques. Advances in single-molecule detection using fluorescence resonance energy transfer were presented by $\mathrm{H}$. Yang (UC-Berkeley). In a session on colloidal and nanoparticle synthesis and assembly, T. Emrick (Univ. of Massachusetts, Amherst) presented well-defined polymer nanoparticles containing core, ligand, and periphery chemical functionality, and Y-Y. Won (Purdue) discussed virusmimetic nanoparticles.

\section{Si Nanomembranes, Assessment of Nanotechnology Risk, Illustrations to Communicate Research, and Entrepreneurship Featured in Symposium $X$}

Symposium X, "Frontiers of Materials Research," presented invited talks aimed at nonspecialists given by professionals in the fields of Si nanomembranes, risk assessment in nanotechnology, visual methods at the nanoscale, commercialization of III-V semiconductor materials, and innovation from the laboratory to the market.

Max Lagally (Univ. of Wisconsin, Madison) discussed the unique properties and potential applications of silicon nanomembranes. Si nanomembranes are thin sheets $(10 \mathrm{~nm}$ to several hundred nanometers thick) of strain-engineered Si consisting typically of two or more layers. These sheets are entirely single-crystalline, yet they are as flexible as plastic wrap. The foundation for nanomembrane technology is silicon-oninsulator (SOI), a technology that rests on the ability to bond two Si wafers together through an intermediate oxide. The oxide can be etched without etching the $\mathrm{Si}$, enabling the removal of a thin layer of $\mathrm{Si}$. Strain-engineered $\mathrm{Si}$ nanomembranes result if a very thin film of a lattice-mismatched layer, such as a GeSi alloy, is grown on the $\mathrm{Si}$. The alloy matches the lattice of the $\mathrm{Si}$ but is under stress. If the oxide is then etched, the stress can be relieved, and, depending on how the layer structure is grown, a large variety of shapes of single-crystal membranes (such as flat sheets, tubes, or coils) can be obtained. Essentially, the strain controls the shape, and each shape has its own peculiar properties. Lagally said that potential applications of Si nanomembranes range from electronics to biology.

As research in nanotechnology prevails, so do risk assessments. Cell biologist Harald F. Krug (Forschungszentrum Karlsruhe, Germany) described studies using an in vitro system called the 3D Cell Model, which combines an aerosol of nanoparticles in a container with macrophages, epithelial cells, and endothelial cells in a biological medium, demonstrating that nanoparticles can invade epithelial cells, pass through a membrane, and then attack the endothelial cells on the other side. While other research efforts in both in vitro and in vivo systems are taking place around the world, Krug said that they are being done with nanoparticles of varying properties, making them difficult to compare. Vincent Castranova, a physiologist from the National Institute for Occupational Safety and Health within the Centers for Disease Control and Prevention, presented details of research on the pulmonary toxicity of SWNTs. One study involving laboratory mice revealed that inhaled SWNTs were nontoxic. However, further studies showed significant fibrosis occurring even in the absence of inflammation, an unusual pattern. Chemist Stefan Engel of the Hazardous Chemicals Management division of BASF in Germany reported on studies showing that dermal exposure to engineered nanoparticles in the workplace is probably not hazardous, while inhalation exposure clearly can be, depending on the chemical, physical, and geometric properties of the dust.

Risk assessment of another type was described by Tom Brennan (Zircle LLC, Albuquerque) and Gail K. Naughton (San Diego State University), who chronicled the rise and fall of their respective start-up companies. In the mid-1990s, Brennan started a company making micro-optical devices, with an initial capital outlay of $\$ 3$ million, that was later bought by Emcore for a substantially higher value. While this was a significant success for Brennan, he subsequently joined Zia Laser, another start-up company, that was not as successful. Naughton is the former founder and president of Advanced Tissue Sciences, which produced Transcyte ${ }^{\mathrm{TM}}$, a temporary wound cover that aided in the treatment and healing of full- and partial-thickness skin burns, and Dermagraft ${ }^{\mathrm{TM}}$, a permanent skin implant that aided in chronic wound closure, such as foot ulcers in diabetic patients. The success of Transcyte in easing the pain of burn victims and restoring their skin to near its original condition made the investment seem like a sure thing. However, overly optimistic estimates by business analysts placed the market for skin graft products for burn victims at $\$ 100$ million per year, when it proved to be only about $\$ 5$ million per year, and the company, like several other manufacturers in the same field, filed for bankruptcy. Naughton said that the rights to their products were sold, however, so Transcyte and Dermagraft continue to help patients.

The availability of molecular simulation software has led to an explosion of molecular illustrations, enabling materials researchers to convey scientific information through a variety of visualizations - from 3D, rotating molecular images to "virtual" reality systems that use cameras and feedback loops to demonstrate how a molecule interacts with its surroundings. In his presentation on visual methods, David S. Goodsell (Scripps Research Institute) offered guidelines to help researchers choose their means of illustration. A good illustration emphasizes graphic details without interfering with the science being presented. For example, molecular illustration requires a metaphor, such as bond, space-filling, and cartoon schematics. Each type reveals certain aspects of molecules while obscuring others. The bond metaphor uses lines to represent bonds at the expense of electronic detail; the space-filling model shows the shape, form, and volume of a molecule but obscures any inner structure; and the cartoon schematic typically shows a ribbon structure to represent the topology of a molecule such as DNA, but leaves out any atomic detail. Goodsell advises researchers to learn how to bypass default settings in molecular visualization programs that limit visualization options and to beware of using too many colors, which may obscure the scientific information they are trying to reveal. 
J. Schlenoff (Florida State Univ.) discussed the characterization of polyelectrolyte multilayer and tethered brushes, and P.J. Yoo (MIT) described the use of this technology in controlling the deposition of viruses, while J. Ruhe (Univ. of Freiburg) discussed its significance to smart switchable surfaces. In another session, speakers focused on the kinetics of dissolution of polyelectrolyte thin films and the application of this technology in designing next-generation photoresists.

Symposium Support: NIST.

\section{Unusual Mechanical Behavior of Nanoscale Materials and Devices Explored}

(See MRS Proceedings Volume 924E)

In Symposium Z on Mechanics of Nanoscale Materials and Devices, several presentations highlighted novel experimental techniques to elucidate nanomechanical behavior, such as in situ observation of deformation and fracture of nanoparticles and nanostructured films by nanoindentation in a transmission electron microscope and microcompression testing of focused-ion-beam-machined pillars. TEM observations that revealed novel aspects of deformation behavior of nanostructured materials were discussed, such as grain rotation, viscoplastic deformation twinning, and partial-dislocation-mediated plasticity. The integration of TEM and in situ x-ray diffraction during tensile testing with molecular dynamics (MD) simulations was shown to provide insights on dislocation nucleation, propagation, and absorption at boundaries in nanocrystalline metals. Recent advances were shown in the development of multiscale modeling methods as applied to CNTs, grain-boundary behavior in nanocrystalline materials, and collective and cooperative materials phenomena at the nanoscale. Unusual deformation behavior of nanoscale films and multilayers was discussed, such as the formation of grainboundary wedges, improved fatigue resistance, and high resistance to slip transmission across incoherent interfaces due to core spreading of glide dislocation along the interfaces that are relatively weak in shear. In the area of small-scale devices, key topics highlighted were strain-induced self-assembly of quantum dots and wires and quantum mechanical harmonic oscillators. Several presentations highlighted recent MD simulations that revealed unusual elastoplastic behavior and deformation mechanisms in amorphous silica and metallic nanowires. Models for brittle fracture at room temperature and superplastic deformation at elevated temperatures of CNTs were also presented.

\section{Chemical Energy Converted to}

Mechanical for Molecular Motor Devices (See MRS Proceedings Volume 944E)

In Symposium AA on Molecular Motors, Nanomachines, and Engineered Bio-Hybrid Systems, Z. Guan (UC, Irvine) presented "saw-toothed" forceextension curves for his biomimetic polymers based upon the muscle protein titin. These polymers have designed modular domains, similar to titin, that unfold in a one-at-a-time fashion upon elongation. The modular design enhances both the material toughness and strength.

D. Altman (Stanford) provided evidence that inhibition of bound-ADP release from the motor protein myosin VI converts the motor into an anchor. A. Flood (Indiana Univ.) acknowledged the significance of Altman's myosin anchor, suggesting that "anchoring" should be considered when constructing molecular motor arrays. Flood presented force measurements for palindromic 3-rotaxane synthetic motors. These small bistable motors, when applied in large numbers, are capable of bending cantilevers.

Controlled actuation was a recurrent theme for both polymeric actuators and engineered kinesin/microtubule systems. P. Palffy-Muhoray (Kent State Univ.) envisions using the responsive properties of liquid crystal elastomers (LCE) to develop sensors, switches, and motors. R. Zentel (Univ. of Mainz, Germany) has synthe- sized polysiloxanes containing azo dyes forming photoactivated actuators. Here, photoactivation of the polymer, whether in LC phase or in solution, changes its molecular tilt. H.L. Ricks-Laskoski (NRL) has developed electric-field-activated polymeric actuators. Craftily engineered microtubule systems were presented by C. Reuther (MPI, Dresden), who created submicrometer-sized nanotracks for microtubule transporters on unstructured surfaces, and also by E. Spoerke (SNL) and $\mathrm{H}$. Hess (Univ. of Florida, Gainseville), who formed circularized microtubule transporters. Hess also presented an overview of concepts and techniques guiding the integration of molecular motors into devices.

Symposium Support: AFOSR; Andor Technology; Cytoskeleton Inc.; and GeSiM.

\section{Mechanical Stimulation and}

Manipulation of Cell Surfaces Presented (See MRS Proceedings Volume 925E)

A highlight of Symposium BB on Mechanotransduction and Engineered Cell-Surface Interactions was the Springer Prize lecture by Viola Vogel (ETH Zurich), whose work on force effects on proteins has opened new directions for active surfaces and adhesion. Physical force effects on cell viability and function were further discussed by J. de Pablo (Univ. of Wisconsin) as well as new techniques for measuring cell forces. Descriptions were given

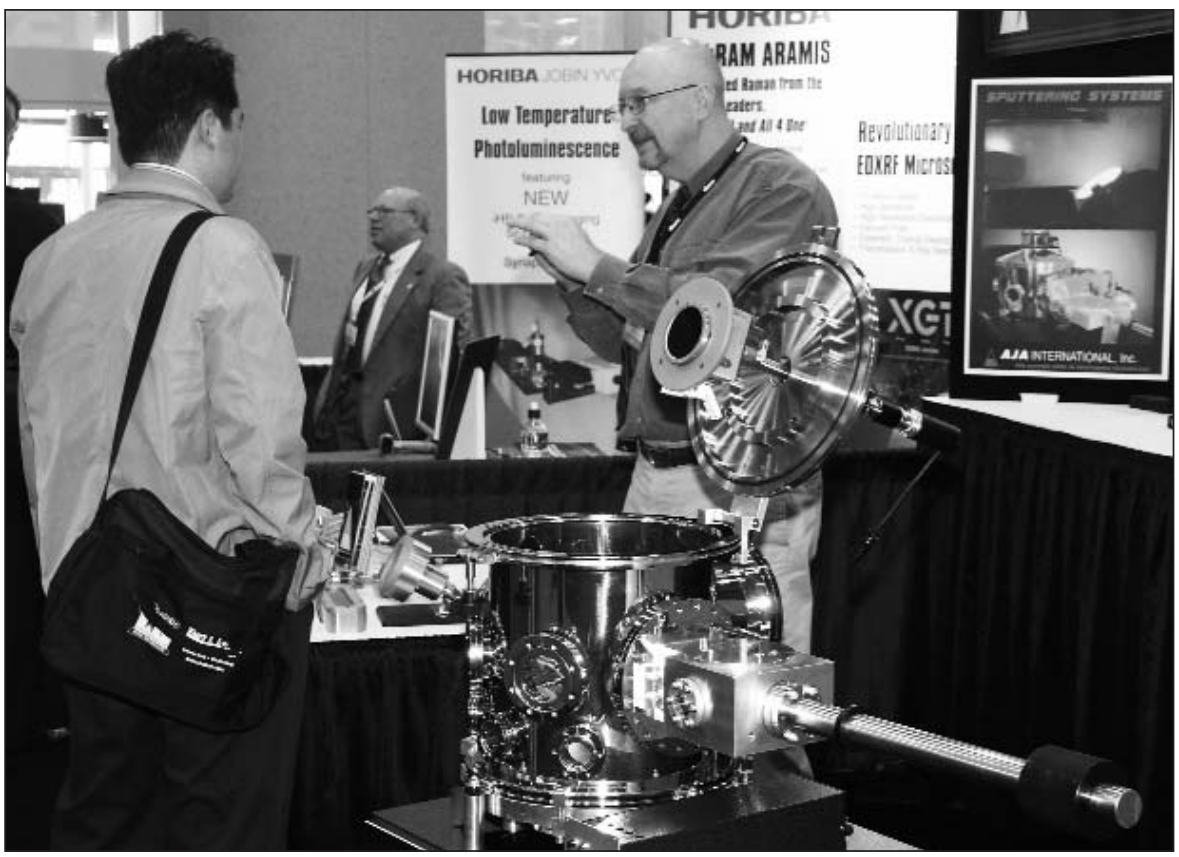

As a complement to the 2006 MRS Spring Meeting, an equipment exhibit was held, showcasing the latest equipment and technology developments available for materials research. 
of the use of micro- and nanopatterned surfaces for the modulation of cell shape and differentiation (P. Nealy, Univ. of Wisconsin) or for modifying immune function (J. Groves, UC-Berkeley).

Another important area featured was the development and characterization of fibrous arrays with novel chemical functionality that would be able to stimulate cell growth and/or differentiation for tissue engineering applications. Talks ranged from self-assembled fibers with specific chemistries (S. Stupp, Northwestern) to the patterning of specific fibers for eliciting specific cellular responses (D. Lee, Univ. of London; G. Fuller, Stanford; and L. Shea, Northwestern). In addition, there were discussions of gel properties for stem cell growth (J. Elisseeff, JHU).

\section{Electronic Device-Biospecimen Interfaces on Compliant Substrates Developed \\ (See MRS Proceedings Volume 926E)}

The main challenges encountered when designing bioelectronic interfaces were reviewed by D. Martin (Univ. of Michigan) in Symposium CC as (a) biological: inert to the living environment; (b) mechanical: hard to soft materials; (c) electrical: electron to ion transfer; and (d) structural: dry and planar to wet and articulated devices.

A number of talks captured recent advances on electrode coatings increasing electrode-tissue charge transfer and reducing chronic tissue response. In particular, PEDOT matrices on gold electrodes and PEDOT- and PPy/PSS-coated nanotubes show improved (low) impedance, and provide a compliant, mechanical buffer layer to interface with the biological tissues. Several research groups focused on encapsulation materials such as parylene, silicone, and polymer nanocomposites (D. Tyler, Case Western) that can flex and stretch along with the biological tissues, promising more reliable recordings of neuron activity and longterm implantation.

D. Kipke (Univ. of Michigan) and P. Koch (IBMT, Germany) introduced a generation of flexible recording/stimulating probes: parylene-based microfabricated multichannel implantable devices. Such probes were successfully implanted in the cortex (Kipke) and along peripheral nerves (Koch), showing reduced physical damage to cells and surrounding tissues. Fully flexible, integrated systems on a compliant substrate made of a biosensor, an electrical connector, and integrated circuits were presented for implantable neuroengineering applications (Koch's group; A. Nurmikko, Brown; and L. Lee, UC-Berkeley) and elec-

\section{Ju Li Addresses Defect Nucleation in OYI Award Lecture}

Defect nucleation plays a critical role in the mechanical behavior of materials, especially if the system size is reduced to the submicron scale. Ju Li of the Ohio State University addressed this topic in his Outstanding Young Investigator Award lecture. At the most fundamental level, defect nucleation is controlled by bond breaking and reformation events, driven typically by mechanical strain and electronegativity differences. For these processes, atomistic and first-principles calculations are uniquely suited to provide an unprecedented level of detail. Several connecting threads incorporating notions in continuum mechanics and explicit knowledge of the interatomic energy landscape can be identified, such as homogeneous versus heterogeneous nucleations, cleavage versus shear-faulting tendencies, chemomechanical coupling, and the fact that defects are singularities at the

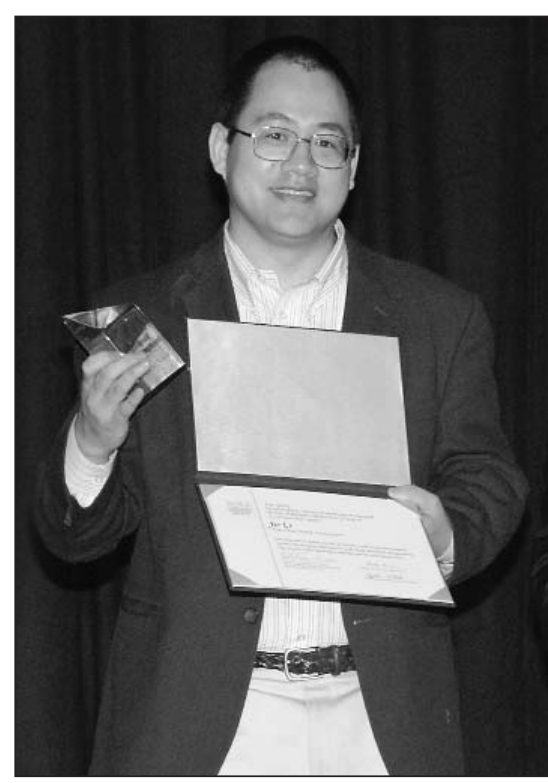
continuum level but regularized at the atomic scale.

Li presented a number of examples chosen from nanoindentation, crack-tip processes, and grain-boundary processes. Besides identifying candidate mechanisms, ideal strength, activation energy, and activation volume are quantitative information that the calculations can provide to validate against experiments. One example described by Li was stress corrosion cracking of silica by water, wherein at low stress levels, chemical attacks lead and mechanical effects follow. At intermediate stress levels, mechanical and chemical effects are similar and neither dominates. At high stress levels, however, mechanical effects lead while chemical effects follow. Li said that much research has yet to be done in the mechanics and physics of materials, providing a bright future for students in this field.

tronic skin (T. Someya, Univ. of Tokyo).

A few talks showed that bioelectronic interfaces on plastic are also an effective technology for in vitro instrumentation platforms for brain trauma study, and for DNA/protein detection and immobilization.

Symposium Support: ALA Scientific Instruments Inc.; Dow Corning Corp.; MultiChannel Systems; and Plexon Inc.

\section{Improved Efficiency and Remaining Challenges of Solid-State Lighting Examined}

(See MRS Proceedings Volume 916)

Materials discussed in Symposium DD on Solid-State Lighting Materials and Devices included a broad range of currentinjected and photoexcited organic and inorganic materials. Highlights featured a detailed analysis of the materials challenges for viable organic sources, novel backlighting units for television sets, and the presentation of a 28,000-lumen solid-state source that emits light equal to $3060-\mathrm{W}$ light bulbs. The development of organic and inorganic materials and their use in solid- state lighting devices is anticipated to result in substantial reductions in globalwarming-related gas emissions, acid-raincausing emissions, and dependency on oil.

Symposium Support: GE and LANL.

\section{Innovative Hydrogen Storage \\ Concepts Presented}

(See MRS Proceedings Volume 927E)

The topics of metal and chemical hydrides, CNTs, carbon buckyballs, and metalorganic framework were covered in Symposium EE on Hydrogen Storage Materials. D. Mori (Toyota) described an innovative hydrogen storage tank design that can provide up to $9 \mathrm{~kg}$ of onboard hydrogen in about the same space as current gasoline fuel tanks. However, it is much too heavy to be implemented for commercial use. T. Autry (PNNL) presented an overview of hydrogen storage systems using boron-containing materials, which is one of the main thrust areas of the DOE Chemical Hydride Center of Excellence. A. Dillon (NREL) introduced developments in carbon-based hydrogen storage systems at the DOE Carbon-Based 
Hydrogen Storage Center of Excellence. G. Pez (Air Products) addressed hydrogen storage and delivery infrastructure issues and potential candidate materials being developed for those applications. W. Luo (SNL) presented recent developments in Li-Mg-N-H systems for hydrogen storage and addressed some critical issues associated with this class of materials for practical applications.

Symposium Support: Toyota Motor North America Inc.

\section{Progress Seen in Basic Solar Research} (See MRS Proceedings Volume 945E)

The purpose of Symposium FF on Materials and Basic Research Needs for Solar Energy was to explain the proceedings and conclusions of a workshop organized by the U.S. Department of Energy on basic research needs for solar energy utilization held in April 2005. The symposium also elucidated new funding opportunities in basic solar research that have recently become available because of the success of the workshop. Invited lectures covered advances made in molecular, organic, and hybrid organic-inorganic solar cells; recent progress in understanding biological photosynthesis as well as artificial photosynthesis; advances made in nanostructures and quantum dots, PVs, and photocatalysis; and developments in dye-sensitized solar cells.

Symposium Support: NREL.

\section{Sol-Gel Method Helps Control Shape and Size of ZnO Nanostructures}

(See MRS Proceedings Volume 928E)

$\mathrm{ZnO}$ is a wide-bandgap semiconductor with high excitonic binding energy and high luminescent efficiency at room temperature. Such features make it a useful material for many optoelectronic applications. However, the traditional thermal evaporation technique used to produce nanostructured $\mathrm{ZnO}$ particles provides no control over the yield of a desired particle shape or size: nanowires, nanorods, and nanotubes occur along with other structures in an undifferentiated mixture.

In order to gain some control of $\mathrm{ZnO}$ microstructures, A. Tiwari and his coworkers at the University of Utah have developed a sol-gel method for producing $\mathrm{ZnO}$ at room temperature, as he reported in Symposium GG on Current and Future Trends of Functional Oxide Films. The technique gives the researchers the ability to synthesize controlled $\mathrm{ZnO}$ nanostructures at desired locations on a substrate. In the process, the research team has learned to make exotic structures that may have practical uses.

By varying the substrate, the substrate temperature, and the molarity of the
$\mathrm{Zn}\left(\mathrm{NO}_{3}\right)_{2}$ precursor solutions, the researchers made $\mathrm{ZnO}$ "flowers" and "spiders" on sapphire substrates and "crosses," "swords," and "pillars" on Si(111) surfaces. Flat planes of $\mathrm{ZnO}$ have also been produced. Some of these microstructures have high surface areas that would make them ideal for sensor applications. Tiwari also said that they can insert $\mathrm{ZnO}$ into the pores of felted fabrics to act as a radiation shield, and can coat $\mathrm{ZnO}$ onto cotton threads to make flexible magnetic sensors.

Symposium Support: Applied Materials Inc.
Progress of Superconducting Wires, Coated Conductors, and New Materials Shown 20 Years after High-Temperature Superconductor Discovery

(See MRS Proceedings Volume 946E)

Twenty years after the discovery of high-temperature superconductors, the progress on their fundamental understanding and the path toward industrial applications has been significant. First-generation $(1 \mathrm{G})$ wires are now produced in kilometer lengths, while the scale-up of $2 \mathrm{G}$ wires (coated conductors) is progressing at a fast pace. These achievements have been

\section{Women in MS\&E Breakfast Features Panel on Career Experiences}

"If you are miserable, it's not you ... it's where you are."

Find a different job that fits. That was Merrilea Mayo's advice to the crowd of mostly women and some men at the Women in Materials Science and Engineering breakfast held on April 19. Currently, Mayo is director of the GovernmentUniversity-Industry Research Roundtable at the National Academies. As a person interested in everything, but often bored with anything in 5-7 years, Mayo calls herself an expert at how to move from one thing to the next. She moved from metallurgy to ceramics, and now to policy. Indeed, she even said she is good at firing, because she can see when someone else does not fit and would be in a better situation doing something else. The session focused on Women in Science and Engineering Careers: Harnessing Our Strengths for the Long Haul. Mayo gave humorous and insightful hints on how to avoid bad jobs and find a dream job.

She said, "If you wouldn't want to have lunch with your interviewer, run the other way, but more importantly, make sure your values match those of the people and institution you are joining." If it is not the right match, wait for the next one, or create it, she said.

Nancy Yang, a distinguished member of the technical staff at Sandia National Laboratories in California, said that it is not necessary for women to act like their male counterparts in order to succeed. Women need to emphasize their own strengths. Instinct, common sense, and attention to detail are some talents Yang had found can be a benefit in team-building. Having entered the field in mining and metallurgy at a time when she was not allowed in the mine pit because it was considered bad luck for a woman to be there, she said, "We have come a long way."

While a significant fraction of people in the audience still felt they were treated differently because of their gender, several audience members said that now gender seemed like less of a problem than cultural differences due to misunderstandings about customs and expectations. Mayo said that facilitators can help with such cultural differences.

Linda Vanasupa of California Polytechnic State University moderated the panel, which was sponsored by the MRS Public Outreach Committee, FEI Company, and Sigma-Aldrich.

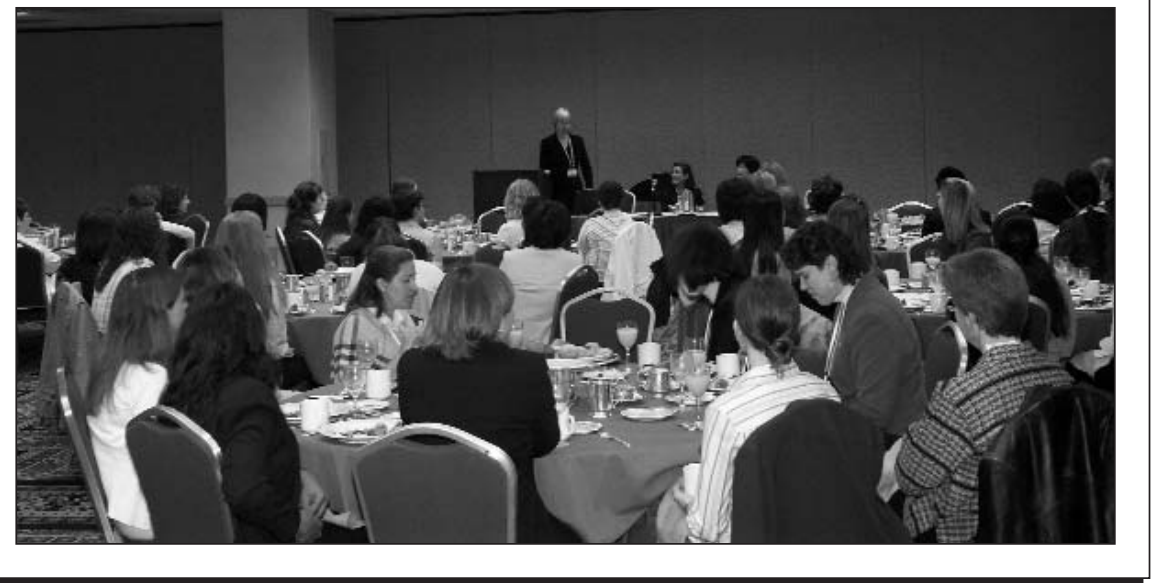


made possible by cutting-edge developments in materials science and technology. A key topic at Symposium HH on Recent Advances in Superconductivity was the enhancement of the in-field critical current by the introduction of appropriate vortex pinning centers. Many speakers showed that large improvements could be obtained through nanoengineering of several types of defects, including the introduction of nanoparticles (J. Thompson, ORNL; B. Maiorov, LANL; K. Matsumoto, Kyoto Univ.; A. Malozemoff, American Superconductor Corp.; T. Haugan, AFRL; Z. Chen, SuperPower; and Y. Yoshida, Nagoya Univ.) and interface manipulation and multilayering (T. Aytug, ORNL; H. Wang, Texas A\&M Univ.; and S. Foltyn, LANL). Progress has also been made in improving the intergrain $J_{c}$ in ex situ films by grain-boundary meandering ( $R$. Feenstra, ORNL; M. Feldmann, Univ. of Wisconsin, Madison; and T. Puig, ICMAB). Y. Shiohara (ISTEC) and H. Freyhardt (Univ. of Göttingen) presented the research and industrial perspective from Japan and Europe, respectively. The importance of understanding structure-property relations and the use of multiscale characterization tools were also emphasized (D. Miller, ANL; J. Reeves, SuperPower; T. Kiss, Kyushu Univ.; and T. Holesinger, LANL). Superconducting $\mathrm{MgB}_{2} \mathrm{~B}$ also attracts large interest due to its high superconducting transition temperature $T_{\mathrm{c}}$ of $\sim 40 \mathrm{~K}$ (the highest among binary compounds), chemical simplicity, low cost of the raw materials, and absence of weaklink limitations that allows the fabrication of wires by powder-in-tube. The inclusion of $\mathrm{MgB}_{2} \mathrm{~B}$ presentations in the symposium was aimed to bring together $\mathrm{MgB}_{2} \mathrm{~B}$ and coated-conductor communities and encourage the discussion of problems common to all superconducting wires. Relevant topics included enhancement of $H_{\mathrm{c} 2}$ by chemical doping (A. Gurevich, Univ. of Wisconsin, Madison; A. Serquis, Bariloche), improved synthesis methods (X. Xi, PSU; L. Cooley, BNL), and wire fabrication and properties (R. Flukiger, Univ. of Geneva; H. Kitaguchi, Tsukuba; and G. Giunchi, Edison SpA).

Symposium Support: LANL and ORNL.

\section{Simulation, Characterization, and Behavior of Materials in Extreme Environments Explored}

(See MRS Proceedings Volume 929E)

Advanced simulation methods, coupled with high-performance computing platforms, now afford predictions-on a firstprinciples basis — of the properties of materials in extreme environments, the topic addressed in Symposium II. Examples of

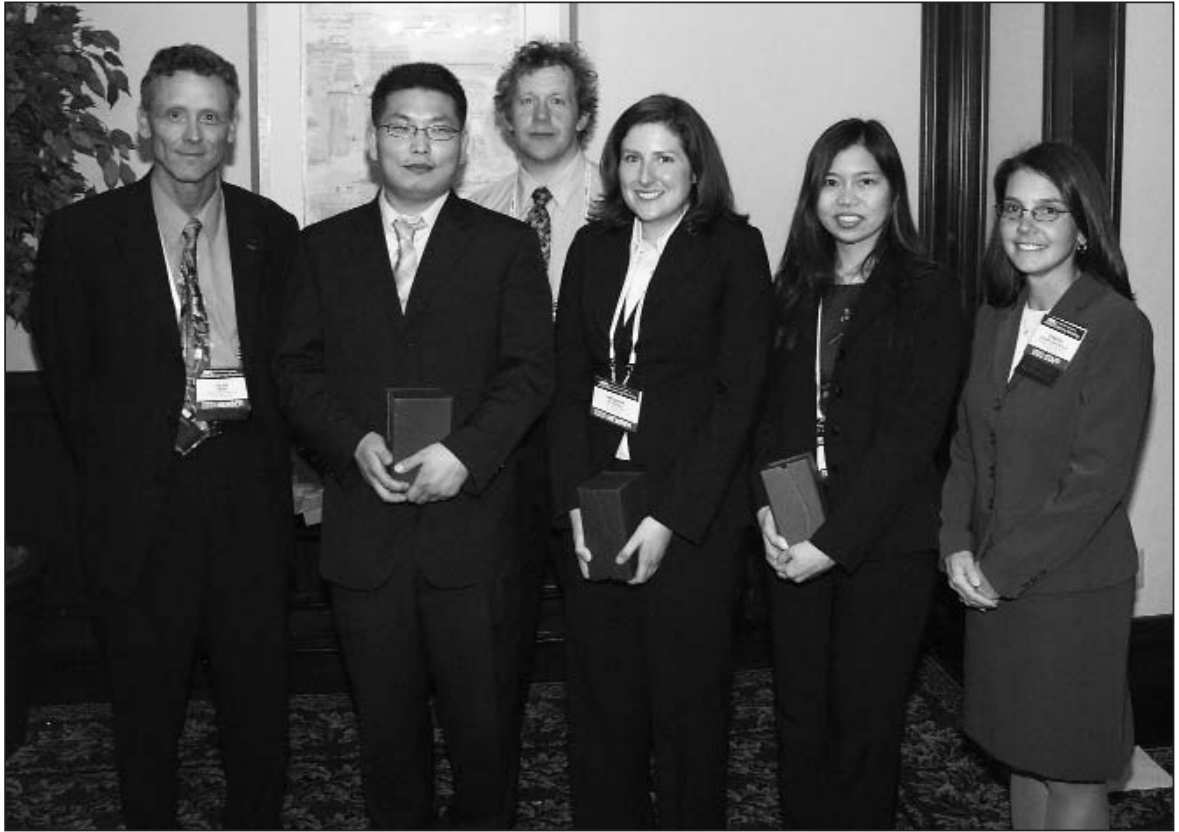

In the MRS Entrepreneurship Challenge, the University of Michigan team received the grand prize of $\$ 3000$ and a laser-etched crystal award for their business plan, "Standard 3D Scaffolds for Stem Cell Research.” (Left to right): Alan Hurd (MRS vice president), Jungwoo Lee (technical lead), Nicholas Kotov (team mentor), Meghan Cuddihy (technical member), Rewadee Chaihetphon (business member), and Sandra DeVincent Wolf (MRS director of planning). Not shown is Oleg Svintsitski (business lead). The competition was designed to help MRS members develop the entrepreneurial skills that get ideas out of the laboratory and directly into the marketplace.

Monte Carlo (MC) simulations to predict the dose to various materials in the extreme Jovian environment were provided by W. Atwell (Boeing, Houston). L. Pinsky (Univ. of Houston) illustrated the use of the multi-physics-based FLUKA MC simulation code in applications ranging from particle accelerator design to radiation therapy for cancer treatment. Several presentations touched on the topic of static and dynamic high-pressure research, highlighting the state of the art both in experimental and computational investigations. G.W. Lee (LLNL) introduced the dynamic diamond-anvil cell (d-DAC) experimental method to investigate kinetic effects across phase transformation. In particular, he demonstrated how water can be compressed into two different forms of ice by applying different kinetic pathways. A. Jankowski (LLNL) discussed the use of laser-driven dynamic compression to investigate microstructure evolution during shock melting and rapid re-solidification in pre-heated $\mathrm{Bi}$ and $\mathrm{Bi}(\mathrm{Zn})$ samples. Y. Picard (Univ. of Michigan) illustrated the uses of high-intensity, ultrafast lasers to investigate ignition and mixing in reactive multilayers.

In the area of quantum-based simula- tions of materials, J. Ciezak (ARL/NIST) discussed the application of modern $a b$ initio total energy electronic structure methods based on density functional theory (DFT) to predict the molecular structure and equation of state of the explosive RDX under hydrostatic compression. In particular, she discussed the limitations of DTF methods to quantitatively capture the weak intermolecular van der Waals interactions at low pressure.

Also on the topic of $a b$ initio simulations of materials, M. Hebbache (Université Paris 7) discussed predictions of the atomic structure of osmium diboride, a novel hard material. Hebbache and his colleagues confirmed the existence of $\mathrm{OsB}_{1.1}$, $\mathrm{Os}_{2} \mathrm{~B}_{3}$, and $\mathrm{OsB}_{2}$ (osmium diboride). Microindentation hardness experiments show that the orthorhombic $\mathrm{OsB}_{2}$ phase has a hardness of $36 \mathrm{GPa}$, just under the values of 40-50 GPa reported for $\mathrm{BN}$ and 60-70 GPa for diamond. Also, first-principles calculations reveal that $\mathrm{OsB}_{2}$ is less compressible than diamond, raising the possibility that it could be used as a superhard industrial coating.

Symposium Support: LLNL and NASA University Research Centers at Alabama AEM Univ. and Prairie View A\&M Univ. 


\section{Water Treatment Gains from Advances in Materials Research} (See MRS Proceedings Volume 930E)

Speakers in Symposium JJ on Materials Science for Water Treatment discussed using new materials systems for water treatment; synthesizing new materials and developing new methods of synthesis; and investigating and modeling interactions between constituents in water and materials and methods of characterizing the interactions. Among the highlights reported was the synthesis of new homogeneous and heterogeneous flocculants and coagulants, where a well-known alum-based flocculant was combined with a well-known polyionic amphiphile to create a new materials system with properties that can separate non-enveloped viruses to below the PCR detection limit (M. Nyman, SNL). The synthesis of new amphilic copolymers was presented, which demonstrated antifouling resistance to proteins of nanofiltration and reverseosmosis membranes (A. Mayes, MIT). DNA materials were synthesized with the ability to sense and quantify trace contaminates such as $\mathrm{Pb}, \mathrm{Hg}$, and $\mathrm{As}$ ions in water to the ppb level (Y. Lu, UIUC). Titanate nanofibers were presented for enhancing separations (C.J. Curtis, NREL). Synthetic water channels reminiscent of aquaporins were presented that consisted of self-assembled silica-based structures (J. Brinker, SNL). Key areas of research include new analytic and modeling approaches to understanding the complex interactions in filter media. This was studied by sum frequency vibrational spectroscopy for the competitive molecular absorption (L. Zhang, UC-Berkeley), and transport of ionic species with nylonbased monolayers on membranes was investigated (B. Bunker, SNL). Numerous characterization methods were introduced, from using a photothermal method to extract the Soret coefficient to a look at the thermodiffusion of nanoparticles in water (D. Cahill and S. A. Putnam, UIUC), RBS for partitioning of arsenic in membranes (B. Mi, UIUC), and MRI for the diffusion tensor of water within hydrogels (G. Raguin, UIUC).

Symposium Support: Center for Advanced Materials for Purification of Water with Systems (WaterCAMPWS), UIUC/NSF.

\section{Nanoscience Finds Its Way into Education}

(See MRS Proceedings Volume 931E)

The recent emergence of nanoscience/ engineering/technology (NSET) as a major activity across science, technology, engineering, and mathematics disciplines is bringing with it changes in university teaching to convey the abstract and unfamiliar concepts of the nanoworld to students. Presenters at Symposium KK, Education in Nanoscience and Engineering, described current teaching strategies at colleges, research universities, and contributing research institutions. H. Kroto (Florida State Univ.) defined abstract nanoscale architecture concepts using $C_{60}$ and nanotubes and established the importance of teaching nanoscale and mathematical concepts across the curriculum. For undergraduate instruction at colleges, educational projects emphasized student nanoparticle synthesis and properties measurement, nanocharacterization experiments, and scanning probe microscope construction. Widespread interest in societal and ethics issues related to NSET education and deployment was addressed by several speakers. The ability to synthe- size, characterize, and visualize nanomaterial and device architecture is central to attracting vigorous and enthusiastic students; this requires a wide array of complex and expensive equipment and infrastructure. Fortunately, a number of major research universities and national laboratories are establishing interactive programs to make these facilities available to colleges across the educational spectrum. In situ, real-time atomic-resolution microscopies are being used to display nanotube synthesis for students. Presenters emphasized the importance of teaching students to think and visualize in the abstract nanoworld. Given this level of abstraction, it was not surprising that many presenters noted the need for improved student mathematical capability. A new, large math teaching research project for STEM/NSET educational goals typical of several in the United States was presented by M. Carlson (Arizona State Univ.). Presenters from major chemical (J. Liu, Monsanto) and electronics (H. Coufal, Nanoelectronics Res. Corp.) industries emphasized the importance of NSET for economic growth; they view NSET as an interdisciplinary, teambased activity built on a firm science and math base. There are some newly established NSET degree programs at all three degree levels worldwide, and interdisciplinary programs are the majority everywhere. NSET educational programs in Japan are notable for the complex instrumentation devoted to them. The abstract nature of NSET is bringing instrumentation, computer visualization and modeling, the Internet, and mathematics into education more strongly than seen before.

Symposium Support: Allied High Tech Products Inc.; Arizona State Univ.; E.A. Fischone Instruments Inc.; FEI Co.; Gatan Inc.; and JEOL USA Inc. MाRS

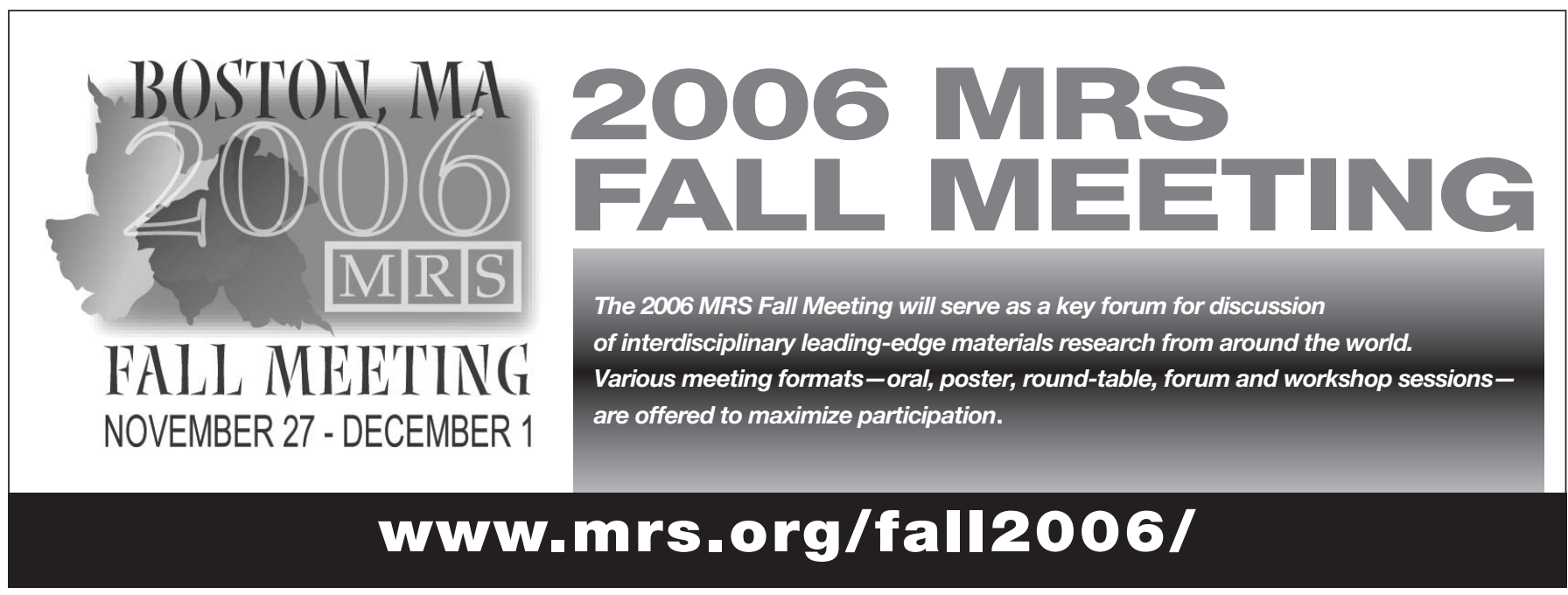

